\title{
¿Synoptic-Scale Environments and Precipitation Morphologies of Tornado Outbreaks from Quasi-Linear Convective Systems in the United Kingdom
}

\author{
TY J. BUCKINGHAM \\ Centre for Atmospheric Science, Department of Earth and Environmental Sciences, University of \\ Manchester, Manchester, United Kingdom \\ DAVID M. SCHULTZ \\ Centre for Atmospheric Science, Department of Earth and Environmental Sciences, and Centre for \\ Crisis Studies and Mitigation, University of Manchester, Manchester, United Kingdom
}

(Manuscript received 4 February 2020, in final form 5 June 2020)

\begin{abstract}
Nine tornado outbreaks (days with three or more tornadoes) have occurred in the United Kingdom from quasi-linear convective systems (QLCSs) in the 16 years between 2004 and 2019. Of the nine outbreaks, eight can be classified into two synoptic categories: type 1 and type 2. Synoptic categories are derived from the location of the parent extratropical cyclone and the orientation of the surface front associated with the QLCS. Environmental differences between the categories are assessed using ERA5 reanalysis data. Type 1 events are characterized by a confluent $500-\mathrm{hPa}$ trough from the west, meridional cold front, strong cross-frontal wind veer (about $90^{\circ}$ ), cross-frontal temperature decrease of $2^{\circ}-4^{\circ} \mathrm{C}$, prefrontal $2-\mathrm{m}$ dewpoint temperatures of $12^{\circ}-$ $14^{\circ} \mathrm{C}$, a prefrontal low-level jet, and prefrontal $0-1$ - and $0-3-\mathrm{km}$ bulk shears of 15 and $25 \mathrm{~m} \mathrm{~s}^{-1}$, respectively. In contrast, type 2 events are characterized by a diffluent $500-\mathrm{hPa}$ trough from the northwest, zonal front, weaker cross-frontal wind veer $\left(\leq 45^{\circ}\right)$, much smaller cross-frontal temperature decrease, lower prefrontal $2-\mathrm{m}$ dewpoint temperatures of $6^{\circ}-10^{\circ} \mathrm{C}$, and weaker prefrontal $0-1$ - and $0-3-\mathrm{km}$ bulk shears of 10 and $15 \mathrm{~m} \mathrm{~s}^{-1}$, respectively. Analysis of the Met Office radar reflectivity mosaics revealed that narrow cold-frontal rainbands developed in all type 1 events and subsequently displayed precipitation core-and-gap structures. Conversely, type 2 events did not develop narrow cold-frontal rainbands, although precipitation cores developed sporadically within the wide cold-frontal rainband. Type 1 events produced tornadoes $2-4 \mathrm{~h}$ after core-and-gap development, whereas type 2 events produced tornadoes within $1 \mathrm{~h}$ of forming cores and gaps. All events produced tornadoes during a relatively short time period $(1-3 \mathrm{~h})$.
\end{abstract}

\section{SIGNIFICANCE STATEMENT}

A total of $22 \%$ of tornado outbreaks (days with 3 or more tornadoes) in the United Kingdom occur with convective storms where heavy precipitation occurs in a line over $100 \mathrm{~km}$ long. Such outbreaks fall into two types. The first is a south-north-oriented cold front with a strong wind shift, producing tornadoes within $2-4 \mathrm{~h}$ after a characteristic precipitation structure called cores and gaps develops. The second is a west-eastoriented front with a weaker wind shift, producing tornadoes within $1 \mathrm{~h}$ after core-and-gap formation. These results point the way toward better understanding of the conditions under which tornadoes form in the United Kingdom, and they suggest that future studies may show that the mechanisms producing tornadoes differ between these two types of storms.

Denotes content that is immediately available upon publication as open access.

\section{Introduction}

Tornadoes are typically a phenomenon associated with the infamous Tornado Alley in the United States,
Corresponding author: David M. Schultz, david.schultz@ manchester.ac.uk
This article is licensed under a Creative Commons Attribution 4.0 license (http://creativecommons.org/ licenses/by/4.0/). 
despite tornadoes having been recorded on every continent except Antarctica (e.g., Snow and Wyatt 1997; Goliger and Milford 1998). In fact, the United Kingdom has experienced more tornado reports per unit area than any other country worldwide (Reynolds 1999; Mulder and Schultz 2015) with 1241 tornado reports recorded between 1980 and 2012, leading to approximately 30-50 reports annually (Mulder and Schultz 2015). Although typically weak and short lived, some U.K. tornadoes in recent history have been destructive. For example, the London F2 tornado on 7 December 2006 injured 6 (e.g., Clark 2011).

The potential for damage and casualties justifies the need to better understand and predict tornadoes in the United Kingdom. Many climatologies have been constructed to determine the distribution of tornado reports, times, and seasons of occurrence (e.g., Elsom 1984; Reynolds 1999; Tyrrell 2003; Holden and Wright 2004; Kirk 2014; Mulder and Schultz 2015; Clark and Smart 2016; Kirk et al. 2016). Less work has been done on understanding the morphologies of the convection that spawns the tornadoes. Several case studies have attributed some tornado events in the United Kingdom to convection having linear morphologies (e.g., Meaden 1976b; Elsom 1985; Meaden and Rowe 1985; Smart and Browning 2009; Apsley et al. 2016), called quasi-linear convective systems (QLCSs) by Trapp et al. (2005). Several submorphologies of QLCSs exist, including squall lines, bow echoes, and narrow cold-frontal rainbands. The majority of U.K. QLCSs are classified as narrow cold-frontal rainbands, where narrow intense bands of precipitation [between 2 and $5 \mathrm{~km}$ in width; James and Browning (1979)] develop within varying shapes and scopes of stratiform precipitation, although pre and postfrontal lines have also been documented (e.g., Clark 2013). The prevalence of U.K. QLCS tornadoes did not become fully apparent until the climatology of Mulder and Schultz (2015), in which QLCSs were shown to be responsible for $42 \%$ of tornado days and $51 \%$ of tornado outbreaks [days of three or more tornadoes, as defined by Mulder and Schultz (2015)] between 2004 and 2012. [An independent analysis by Clark and Smart (2016) found that $43 \%$ of U.K. tornadoes were associated with linear convective systems.] In contrast, a three-year study by Trapp and Weisman (2003) in the United States found only 18\% of tornado reports were attributed to QLCSs, implying differences in tornadic storms between the United States and the United Kingdom.

The majority of tornadic U.K. QLCSs occur in the cool season (autumn-winter) (e.g., Holden and Wright 2004; Clark 2013; Mulder and Schultz 2015; Kirk et al. 2016), similar to those in the United States (Ashley et al.
2019). In the United Kingdom, Clark (2013) found that the following characteristics indicated a greater likelihood of tornadoes along QLCSs: surface-based CAPE $>200 \mathrm{~J} \mathrm{~kg}^{-1}$, cross-line wind veer $>50^{\circ}$, crossline temperature decrease $>3.0^{\circ} \mathrm{C}$, line-normal forward motion $>15 \mathrm{~m} \mathrm{~s}^{-1}$, and the QLCS being located under the 500-hPa jet core, cyclonic-shear side, or left-exit region. However, Clark (2013) commented on how a "holistic approach" should be taken when applying the criteria because many events displayed much larger values of one parameter but failed to reach the thresholds of others, seemingly implying that the larger values in one compensate for the smaller values in the other. Difficulties in finding quantitative thresholds in sounding-based parameters to discriminate between tornadic and nontornadic events were also highlighted in Mulder and Schultz (2015). Clark and Parker (2014) further assessed differences in tornadic and nontornadic cold fronts based on 15 events ( 7 tornadic and 8 nontornadic). They found that tornadic cold fronts exhibited little or no decrease in cross-frontal wind speed, larger cross-frontal wind veer $\left(>45^{\circ}\right)$, and a surge in postfrontal pressure.

Convective systems occurring in environments with little or no instability and high wind shear often occur in the cool season. Such storms have been studied in the U.S. (e.g., Burke and Schultz 2004; van den Broeke et al. 2005; Sherburn and Parker 2014; Davis and Parker 2014; King et al. 2017; Sherburn et al. 2016) and Europe (e.g., Gatzen et al. 2020), but have not specifically focused on tornado outbreaks.

Although a handful of previous studies have documented tornadic QLCS environments and precipitation morphologies in the United Kingdom, none have assessed the synoptic-scale environments or focused specifically on tornado outbreaks. Questions therefore remain as to the importance of the synoptic-scale environments and precipitation morphologies for these events. Do all tornado outbreaks from QLCSs occur in similar environments? If not, what are the differences? Are there characteristic precipitation morphologies of tornadic QLCSs, both on the scale of the convective system and microscale structures within the convection? To answer these questions, we examine the synopticscale environments and precipitation morphologies of U.K. tornado outbreaks in this article to see if common features exist within U.K. QLCSs that spawn tornado outbreaks.

The remainder of this paper is organized as follows. In section 2, tornado outbreaks and their parent storm types are identified using the tornado database from the Tornado and Storm Research Organization (TORRO) and the Met Office radar-derived rainfall mosaics. Section 3 explores the synoptic-scale environments of 
each tornado outbreak and introduces a classification scheme consisting of two types, followed by case studies of each of the two types. Section 4 presents synopticscale analyses of the tornado-outbreak environments, comparing across the two types and each of the individual cases. Section 5 assesses the precipitation morphologies of each event, both on the scale of the convective system and microscale structures within the convection. Finally, section 6 summarizes this study.

\section{Data and methods}

The tornado outbreaks examined in this study derive from TORRO's database. TORRO is a U.K.-based nonprofit organization dedicated to the forecasting, verification, assessment, and archiving of severe weather in the United Kingdom and Ireland (Elsom et al. 2001; Meaden 2016). TORRO is notified of a severe weather report from their network of observers, the media, or the general public (Elsom et al. 2001). Reports are assessed, when necessary, by a site investigation where a member of TORRO uses evidence at the site and eyewitness reports to determine the severe weather type. Tornado reports are classified as probable or confirmed. A tornado report is classified as probable if a tornado likely happened yet there is no hard evidence as determined by the site investigator. For example, a semiconsistent damage track with damage attributable to a tornado, but a lack of photographic evidence, is classified as a probable tornado. A report with photographic evidence and a clear damage track is classified as confirmed. All probable and confirmed tornado reports are collected in the TORRO database, the only known source of compiled tornado and waterspout reports for the United Kingdom. The database includes the time (binned into the nearest hour), date, location, intensity, and further information for each report from 1980 to the present day.

Tornado intensities are determined using the international tornado scale, or T-scale. Proposed by Meaden (1976a), the T-scale is derived directly from the Beaufort scale:

$$
B=2(T+4)
$$

where $B$ is the Beaufort-scale value and $T$ the corresponding T-scale value. Therefore, T0 tornado damage (the lowest ranking T-scale value) is the equivalent of B8, or wind speeds of 17-24 $\mathrm{m} \mathrm{s}^{-1}$ (Table 1.1 in Meaden 2016). The T-scale ranges from $\mathrm{T} 0$ to $\mathrm{T} 10$, where $\mathrm{T} 0$ is considered a "light tornado" causing minimum damage compared to a T10, or a "super tornado," which causes immense destruction. The T-scale can be approximately related to the widely used Enhanced Fujita (EF) scale adopted in the United States (Doswell et al. 2009; McDonald et al. 2009), roughly equating as $E F=0.5 T$, rounded down (Brooks and Doswell 2001; Meaden et al. 2007).

However, weak and short-lived tornadoes have been less likely to be reported. Due to the reliance on the general public, there has been considerable inhomogeneity in the information attributed to tornado reports in the database. Some reports have been missing important information on time and location, and they were classified as probable tornadoes partly due to this missing information. For this study, incomplete reports were retained unless critical information was missing. For example, a report with an unknown time or a range of possible times was retained if verified as a confirmed tornado. However, reports that were considered a probable tornado and were missing the time, location, intensity, etc., were rejected. The database was then filtered for tornado outbreaks, yielding 92 tornado outbreaks and an associated 579 tornado reports during 1980-2019.

To determine the parent storm type of each tornado outbreak, the Met Office 5-min 1-km grid-spacing precipitation-rate mosaics were used. The mosaics were generated by the Met Office from a network of 13 C-band radars before 2008 and 15 radars after 2008. Radar scans at five elevations were used to determine the best estimate of rainfall rates at the surface (Kitchen and Illingworth 2011; Antonescu et al. 2013). The archive was limited to April 2004 onward; hence, all tornado outbreaks prior to this date were omitted, leaving 41 tornado outbreaks and an associated 208 tornado reports.

The parent storm type for the 41 tornado outbreaks was classified as QLCS or non-QLCS due to the focus of the present study. Several classifications for QLCSs exist, but all are based upon similar criteria derived from manual analysis of radar reflectivity (Parker and Johnson 2000; Trapp et al. 2005; Gallus et al. 2008). The criteria have often been split into three factors: the length of the system, the intensity of the precipitation and the duration of the system. The main discrepancies between the thresholds for these criteria in these studies were the precipitation rate (derived from radar reflectivity) and length, which vary between 4 and $16 \mathrm{~mm} \mathrm{~h}^{-1}$ and $100-200 \mathrm{~km}$, respectively. However, as U.K. QLCSs were often cool-season phenomena and occur in environments of weak instability (Clark 2013; Clark and Parker 2014; Mulder and Schultz 2015), the lower ends of these thresholds have been taken for this study. Therefore, the following criteria were applied for determining a QLCS: 
- a minimum length of $100 \mathrm{~km}$, with a length at least 3 times the width,

- a minimum duration on radar of $2 \mathrm{~h}$, and

- a minimum near-continuous rainfall rate of $4 \mathrm{~mm} \mathrm{~h}^{-1}$ (32.6 dBZ).

These criteria were consistent with studies of QLCSs in the United States (Ashley et al. 2019). Applying these criteria to the 41 tornado outbreaks resulted in $9(22 \%)$ QLCS tornado outbreaks with an associated 58 tornado reports (Fig. 1) over this 16-yr period, where each of the retained tornado reports in the TORRO dataset was considered an individual tornado. Attributes of each tornado outbreak are shown in Table 1. Clark (2013) found that 27\% of cool-season convective lines produced at least one tornado, so our results are similar to his.

\section{Sea level pressure patterns and archetypes}

Analysis of a series of Deutscher Wetterdienst (DWD) surface charts for each event showed that all of the nine tornado outbreaks occurred from frontal systems associated with extratropical cyclones (Fig. 2). DWD charts were chosen for their simplicity compared to Met Office charts (e.g., Mulqueen and Schultz 2015). Eight of the outbreaks occurred from cold fronts (Figs. 2a-g,i), and the remaining one occurred from an occluded front (Fig. 2h). At the synoptic times closest to each of the tornado outbreaks, five of the extratropical cyclones were located to the north of the United Kingdom (Figs. 2a,b,d,e,g), three occurred over Scandinavia (Figs. 2c,f,i), and one was located over central England (Fig. 2h). Of the five to the north of the United Kingdom, two of the lows were positioned north of Scotland with central pressure values 990-995 hPa (Figs. 2a,d) and the remaining three were near Iceland with deeper central pressures 955-960 hPa (Figs. 2b,e,g). The three located over Scandinavia and the one over central England had central pressures $990-1000 \mathrm{hPa}$. As will be shown in this article, the location of the low pressure center is indicative of a number of different synoptic characteristics that distinguishes each group of tornado outbreaks from the other. Therefore, we introduce a classification scheme: type 1 , type 2 , and unassigned.

The five type 1 events are defined by extratropical cyclones located north of the United Kingdom. These cyclones all moved slowly from west to east (not shown), with cold fronts extending equatorward from either the low pressure center or with a frontal wave along the front (Fig. 2). In each case, the cold fronts were oriented in an approximate north-south (meridional) configuration, moving rapidly from west to east as they traversed the United Kingdom. Meridionally oriented fronts tended to have a sharp surface trough where the isobars often were sharply kinked with a large change in orientation across the front (about $90^{\circ}$ ), indicating a strong veer in wind direction. Prefrontal winds were predominantly southerly, and postfrontal winds were westerly or northwesterly. The exception to this was 25 January 2014 (Fig. 2g), where a sharp surface trough was not present. Type 1 events were largely a coolseason phenomenon.

The three type 2 events were defined by extratropical cyclones located over Scandinavia. These cyclones were either stationary or moving slowly from north to south, with fronts extending from their centers in an approximate east-west (zonal) orientation in all cases except Fig. 2i, where the front extended from a weak frontal wave instead. Two of the events were associated with these fronts (Figs. 2f,i); the third had a different interpretation (Fig. 2c). Whereas the convective line that spawned the tornadoes was about $100 \mathrm{~km}$ behind and parallel to the surface front analyzed on the DWD surface chart (Fig. 2c) and could be considered postfrontal, the convective line occurred in conjunction with an analyzed secondary cold front on the Met Office surface chart (Fig. 3). Secondary cold fronts are commonly analyzed on Met Office surface charts (Mulqueen and Schultz 2015). A third interpretation of this case is that this convective system was associated with what could be identified as the primary cold front, with a prefrontal wind shift and pressure trough $100 \mathrm{~km}$ in advance (i.e., the DWD surface front and the Met Office primary cold front). Such a frontal structure commonly occurs due to a number of different processes, as reviewed by Schultz (2005). Whatever the interpretation, the tornadic QLCS formed along a weak surface boundary that we classify as a type 2 event.

Zonally oriented fronts all moved slowly from north to south and typically had a weaker surface trough with less of a change in isobar orientation across the front $\left(\leq 45^{\circ}\right)$, consistent with a more subtle wind direction change from prefrontal westerlies or northwesterlies to postfrontal northwesterlies or northerlies. Although only three tornado outbreaks fit this type, they did not appear to be attributed to a particular season.

The unassigned event differed from the other events, not matching the criteria of either type. Doswell (1991) discussed the value in maintaining an unclassified category in any classification scheme, and we adopt that approach here. In the unassigned case where the extratropical cyclone was located over central England, all of the tornado reports were associated with a small segment of a cold front extending meridionally away from the low center (Fig. 2h). An argument could be made 

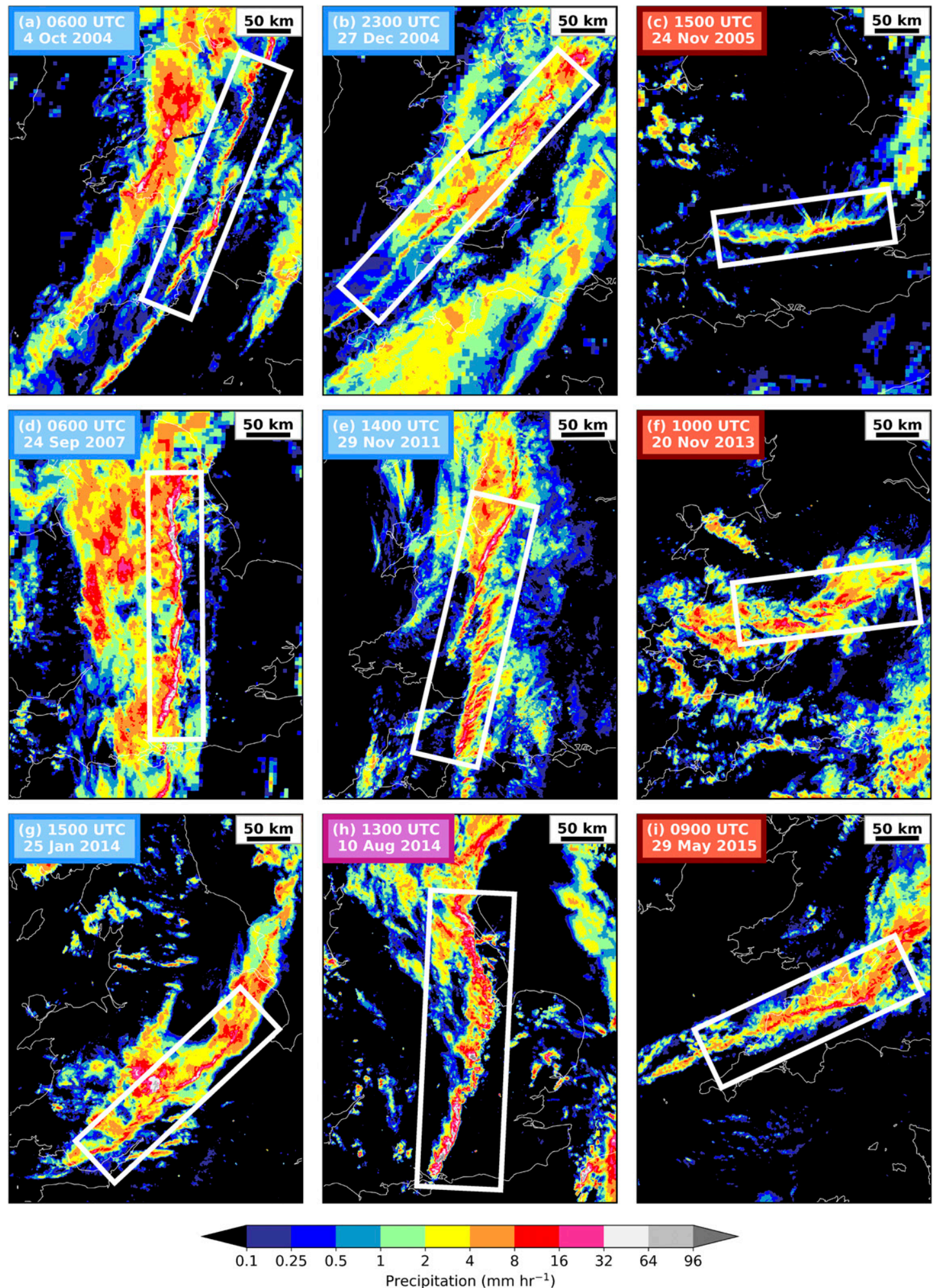

FIG. 1. Precipitation rates of nine QLCS tornado outbreaks: (a) 0600 UTC 4 Oct 2004, (b) 2300 UTC 27 Dec 2004, (c) 1500 UTC 24 Nov 2005, (d) 0600 UTC 24 Sep 2007, (e) 1400 UTC 29 Nov 2011, (f) 1000 UTC 20 Nov 2013 , (g) 1500 UTC 25 Jan 2014, (h) 1300 UTC 10 Aug 2014, and (i) 0900 UTC 29 May 2015. Blue panel labels represent type 1 events, red panel labels represent type 2 events, and the pink panel label represents the unassigned event. Times were selected as the hour with the most reports or the mean hour of reports. White boxes represent the region of the QLCS producing precipitation core-and-gap structures. 
TABLE 1. Attributes of the nine tornado outbreaks. The type labeled "U" is unassigned. Tornado report intensities labeled " $U$ " are unclassified.

\begin{tabular}{|c|c|c|c|c|c|c|c|}
\hline Date & Type & $\begin{array}{l}\text { No. of tornado } \\
\text { reports }\end{array}$ & $\begin{array}{l}\text { Confirmed } \\
\text { tornado reports }\end{array}$ & $\begin{array}{l}\text { Probable } \\
\text { tornado reports }\end{array}$ & $\begin{array}{c}\text { Tornado report } \\
\text { intensities (T-scale) }\end{array}$ & $\begin{array}{l}\text { Duration of tornado } \\
\text { reports }(\mathrm{h})\end{array}$ & $\begin{array}{l}\text { Parent } \\
\text { front type }\end{array}$ \\
\hline 4 Oct 2004 & 1 & 7 & 5 & 2 & $2 \mathrm{~T} 1,1 \mathrm{~T} 2,5 \mathrm{U}$ & 2 & Cold \\
\hline 27 Dec 2004 & 1 & 8 & 7 & 1 & $1 \mathrm{~T} 0,3 \mathrm{~T} 1,1 \mathrm{~T} 1,3 \mathrm{~T} 2$ & 3 & Cold \\
\hline 24 Sep 2007 & 1 & 13 & 5 & 8 & $2 \mathrm{~T} 1,2 \mathrm{~T} 2,9 \mathrm{U}$ & 1 & Cold \\
\hline 29 Nov 2011 & 1 & 7 & 3 & 4 & $2 \mathrm{~T} 1,3 \mathrm{~T} 2,2 \mathrm{~T} 3$ & 2 & Cold \\
\hline 25 Jan 2014 & 1 & 7 & 2 & 5 & $3 \mathrm{~T} 1,4 \mathrm{~T} 2$ & 2 & Cold \\
\hline 24 Nov 2005 & 2 & 7 & 3 & 4 & $1 \mathrm{~T} 0,1 \mathrm{~T} 1,5 \mathrm{U}$ & 2 & Cold \\
\hline 20 Nov 2013 & 2 & 5 & 3 & 2 & $1 \mathrm{~T} 0,2 \mathrm{~T} 1,1 \mathrm{~T} 2,1 \mathrm{U}$ & 2 & Cold \\
\hline 29 May 2015 & 2 & 4 & 2 & 2 & $1 \mathrm{~T} 0,2 \mathrm{~T} 1,1 \mathrm{~T} 2$ & 1 & Occluded \\
\hline 10 Aug 2014 & $\mathrm{U}$ & 5 & 3 & 2 & $3 \mathrm{~T} 1,1 \mathrm{~T} 2,1 \mathrm{U}$ & 2 & Cold \\
\hline
\end{tabular}

that this case could be classified as a type 1 event, although we left it unassigned for four reasons. First, although the cold front was meridionally oriented, the center of the extratropical cyclone was much farther south than all other type 1 events and had a weaker central pressure. Second, the surface trough was weaker than in all other type 1 events. Third, it was the only case of the nine to occur in the summer (10 August 2014). Fourth, a series of individual convective cells developed in a linear orientation (Fig. 1f), which differed from the typical evolution of the narrow cold-frontal rainbands in type 1 events. Therefore, we left it unassigned.

How do these types compare to those in Clark and Parker's (2014) study of U.K. QLCS cold fronts? Type 1 events generally met the tornadic criteria set in Clark and Parker (2014), who, unlike the present study, placed no minimum on the number of tornadoes during an event. None of the three type 2 events or the unassigned event were included in Clark and Parker (2014). A potential reason is the slight difference in definitions between studies. Whereas Clark and Parker (2014) specifically classified a narrow cold-frontal rainband as a continuous line of precipitation, we allowed a nearcontinuous or broken line of precipitation to satisfy the QLCS criteria. All type 2 events lack narrow cold-frontal rainbands prior to the development of linear features; thus, it is not surprising that type 2 events would not meet the criteria of their study.

To provide a more detailed look at the evolution of the surface synoptic charts and morphologies of the radar-derived precipitation, we present case studies of archetypal type 1 and type 2 events. These two cases are representative members of their individual types.

\section{a. Type 1 case study: 24 September 2007}

At 0000 UTC 23 September, an extratropical cyclone was to the northwest of the United Kingdom with a long, weak quasi-stationary cold front extending equatorward over Scotland in a north-northeast-south-southwest orientation; this cold front began developing a frontal wave between 1200 and 1800 UTC (not shown). By 0000 UTC 24 September (Fig. 4a), the frontal wave had nearly developed into a closed central low and was moving to the northeast, with the associated cold front having a nearly meridional orientation by 0600 UTC (Fig. 4b). By 1200 UTC, the cold front had cleared the United Kingdom and progressed over the North Sea (Fig. 4c).

In total, 13 tornadoes were reported with the passage of the cold front between 0500 and 0700 UTC. Of the 13, 5 were confirmed tornadoes and 8 were probable tornadoes. Four were given a strength rating ranging from $\mathrm{T} 1$ to $\mathrm{T} 3$, with the remaining ones unknown. Damage was recorded in the TORRO database in association with the tornadoes, including "upside down caravans, uprooted trees and destroyed bus shelters" along with damage to roofs of buildings. Modeling of this case was conducted by Smart and Browning (2009).

Radar-derived precipitation rates showed a rapid evolution of a narrow cold-frontal rainband along the leading edge of the cold front embedded within the wider cold-frontal precipitation (Figs. 5a-i). At 0000 UTC, as the front moved from the Irish Sea inland, a well-defined narrow cold-frontal rainband with precipitation rates of $>32 \mathrm{~mm} \mathrm{~h}^{-1}$ formed (Fig. 5a), eventually filling in with more area covered by precipitation over the next two hours (Figs. 5b,c). By 0200 UTC, a large fracture was present within the narrow cold-frontal rainband (Fig. 5c). During 0300-0400 UTC, the narrow cold-frontal rainband was exhibiting wavelike features (Figs. 5d,e). By 0500 and 0600 UTC, nearly equally spaced precipitation coreand-gap structures were present along the span of the narrow cold-frontal rainband with precipitation cores exceeding $96 \mathrm{~mm} \mathrm{~h}^{-1}$ locally (Figs. 5f,g). Precipitation gaps are regions with no reflectivity or areas with a relative minimum in reflectivity along the front or convective line. These core-and-gap structures are similar to the lineecho wave pattern (LEWP) first identified by Nolen (1959) and later studied by James and Browning (1979), Locatelli et al. (1995), Jorgensen et al. (2003), Smart and Browning (2009), and Apsley et al. (2016). More will be 

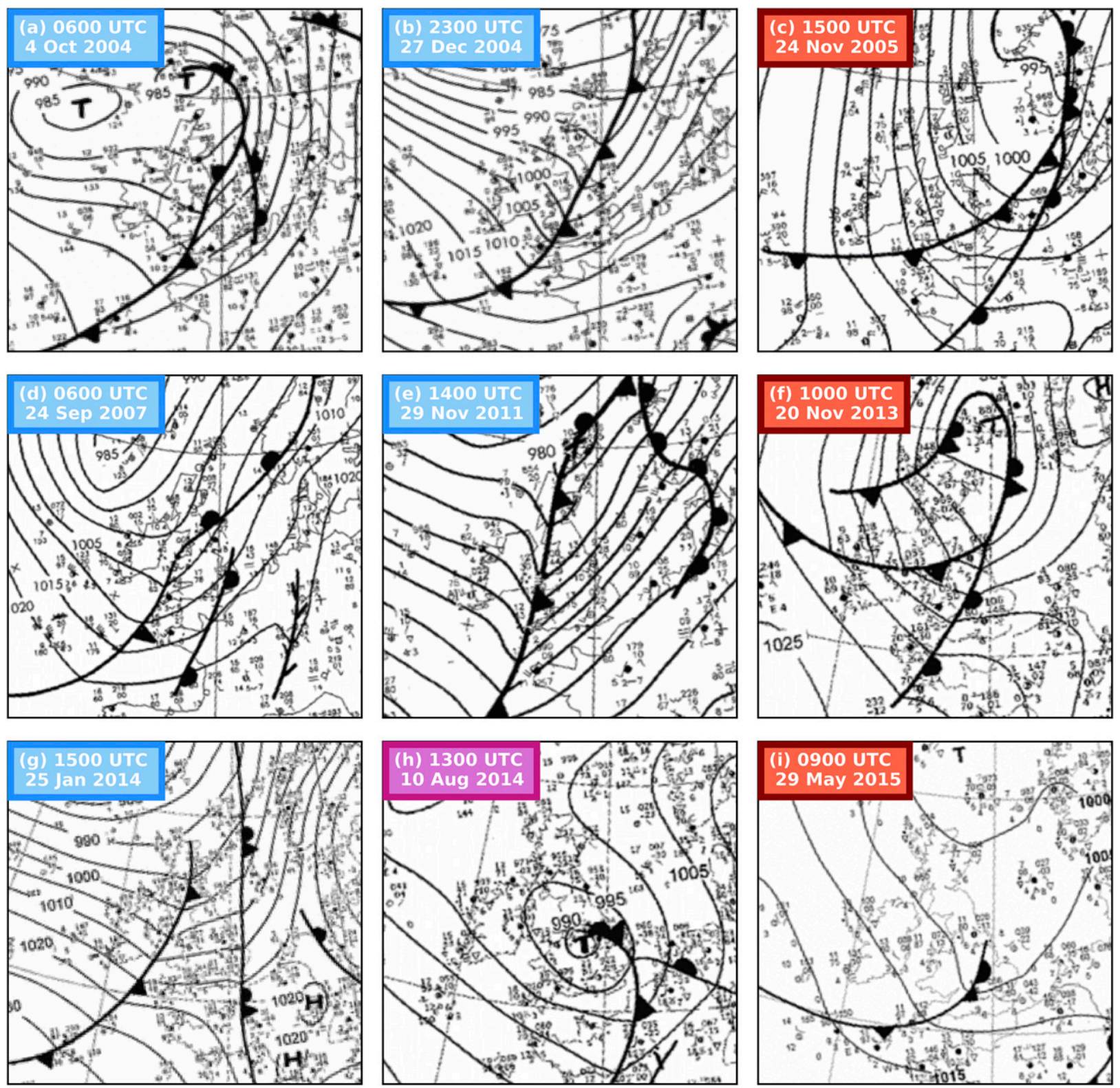

FIG. 2. Surface analysis charts for the closest times available to each of the nine QLCS tornado outbreaks. Blue panel labels represent type 1 events, red panel labels represent type 2 events, and the pink panel label represents the unassigned event. Each chart is within $3 \mathrm{~h}$ of the majority of tornado reports for each event. [The charts were produced by the Deutscher Wetterdienst (DWD) and are available from http://www1.wetter3.de/archiv/.]

said about these structures in section 5 . This structure remained consistent throughout the times of the associated tornado reports. By 0700 UTC, precipitation cores had elongated and weakened (Fig. 5h) and subsequently had dissipated by 0800 UTC as the cold front began to progress over the North Sea (Fig. 5i).

Further analysis of the precipitation structure during the times of the tornado reports shows a variety of smaller-scale features that were potentially attributable to each tornado report (Figs. 5f,g,h). The variety in the relationships between precipitation structures and tornado reports is illustrated in Fig. 6. Four tornadoes reported within the northern segment of the narrow cold-frontal rainband occurred at a time when the narrow cold-frontal rainband was broken up into core-andgap structures, having wavelengths (distance between precipitation core centers) of 20-40 km (e.g., Figs. 6a,b). Six tornado reports in the central segment occurred 


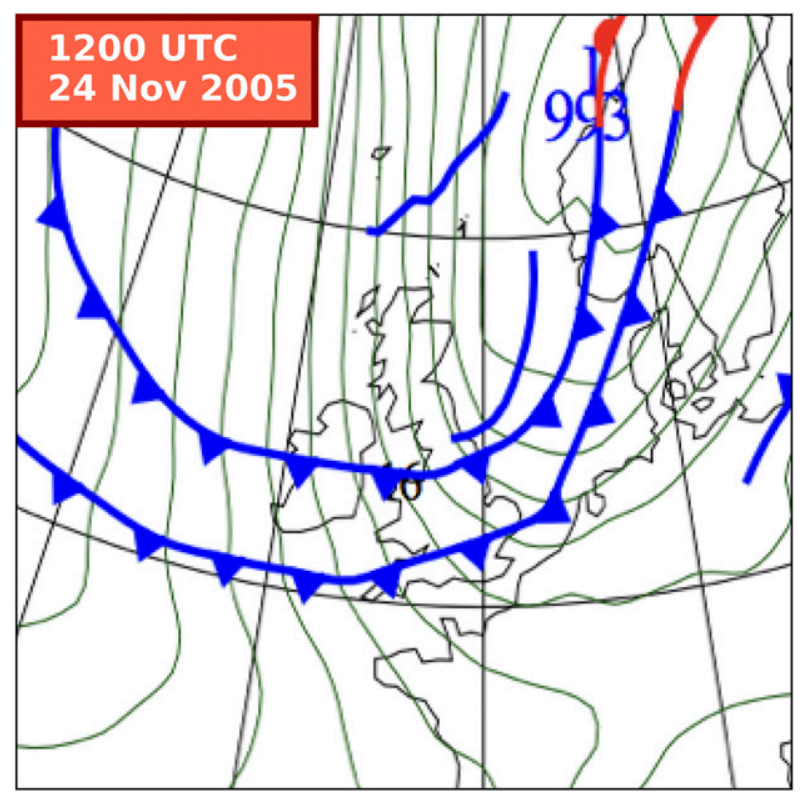

FIG. 3. Surface analysis chart for 1200 UTC 24 Nov 2005. (The chart was produced by the Met Office and is available from https:// digital.nmla.metoffice.gov.uk/.)

along a swathe in which a pair of persistent precipitation gaps were visible within the narrow cold-frontal rainband, which existed for several hours before the tornado reports in the area (e.g., Figs. $6 \mathrm{c}-\mathrm{e}$ ). The remaining three tornado reports all occurred along the southern end of the narrow cold-frontal rainband and can be attributed to precipitation core-and-gap structures that persisted for over $30 \mathrm{~min}$ prior to tornado reports (e.g., Fig. 6f).

\section{b. Type 2 case study: 20 November 2013}

On the morning of 20 November 2013, a cold front associated with an extratropical cyclone traversed the United Kingdom (Fig. 2f). The extratropical cyclone had formed the previous day near Iceland, moving slowly to the southeast (not shown). At 0000 UTC 20 November, a weak warm front was moving from north to south across the central/southern regions of the United Kingdom with the cold front moving into the northern United Kingdom (Fig. 7a). By 0600 UTC, the extratropical cyclone had begun to occlude as it progressed farther southward (Fig. 7b). By 1200 UTC, the cold front was moving over southern United Kingdom and out into the English Channel (Fig. 7c).

Five tornadoes were reported with the passage of the cold front between 0900 and 1100 UTC. Of the five, three were confirmed tornadoes and two were probable tornadoes. Four were given strength ratings, ranging from $\mathrm{T} 0$ to $\mathrm{T} 2$. One report was not allocated a time, but was recorded as a definite tornado due to the damage associated with the report.

Radar-derived precipitation rates showed the evolution of linear features associated with the cold front as it moved into the central United Kingdom (Figs. 8a-i). By 0500 UTC, a few precipitation cells of $>8 \mathrm{~mm} \mathrm{~h}^{-1}$ associated with the cold front were apparent (Fig. 8b). Throughout 0600 UTC and 0700 UTC, a poorly organized line of precipitation exceeding $16 \mathrm{~mm} \mathrm{~h}^{-1}$ locally was spanning the length of the cold front (Figs. 8c,d). At this time, the front displayed similarities to the "brokencell" morphology of QLCSs (Gallus et al. 2008), although embedded cells were sporadic with no clear organization. By 0800 UTC, as the front moved southward, large wavelike structures (wavelength of about $80 \mathrm{~km}$ ) developed along the western side of the cold front with embedded regions of precipitation maxima $\left(>16 \mathrm{~mm} \mathrm{~h}^{-1}\right)$ along the apices of the bowing segments (Fig. 8e). By 0900 UTC, the precipitation had lost the wavelike structure, and a dominant intense cell $\left(>32 \mathrm{~mm} \mathrm{~h}^{-1}\right)$ was present over northwest England (Fig. 8f). Smaller, less
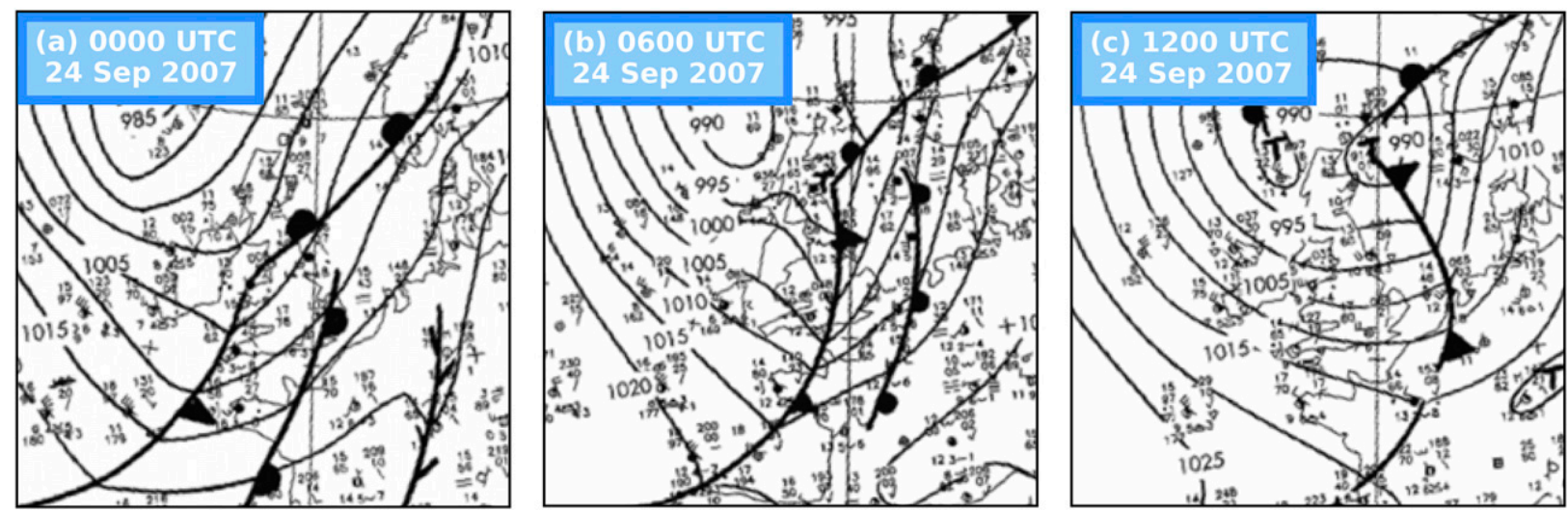

FIG. 4. Surface analysis charts for the passage of a type 1 QLCS tornado outbreak on 24 Sep 2007. [The charts were produced by the Deutscher Wetterdienst (DWD) and are available from http://www1.wetter3.de/archiv/.] 

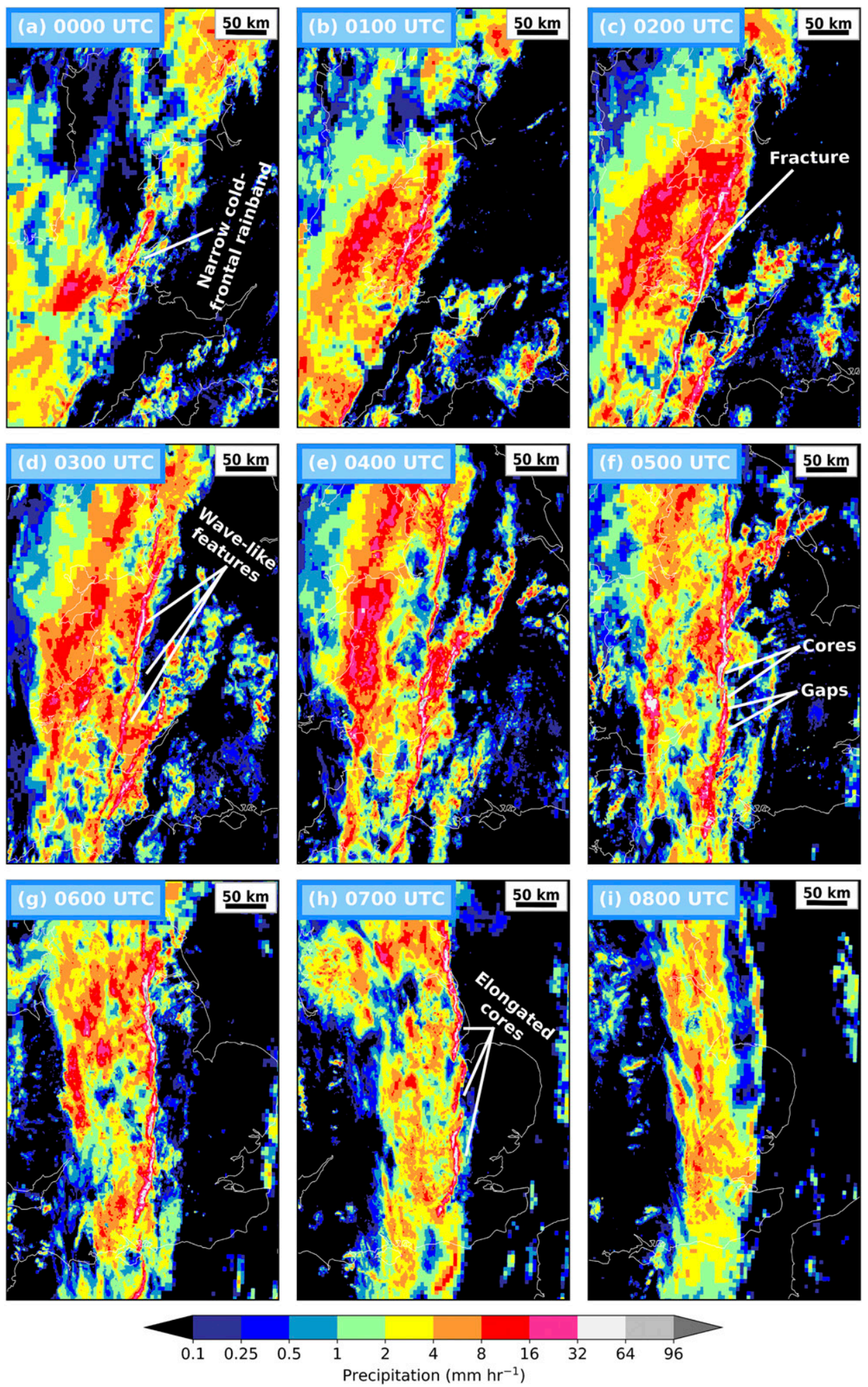

FIG. 5. The evolution of the radar-derived precipitation rate of a type 1 QLCS tornado outbreak on 24 Sep 2007: (a) 0000, (b) 0100, (c) 0200, (d) 0300, (e) 0400, (f) 0500, (g) 0600, (h) 0700, and (i) 0800 UTC. 

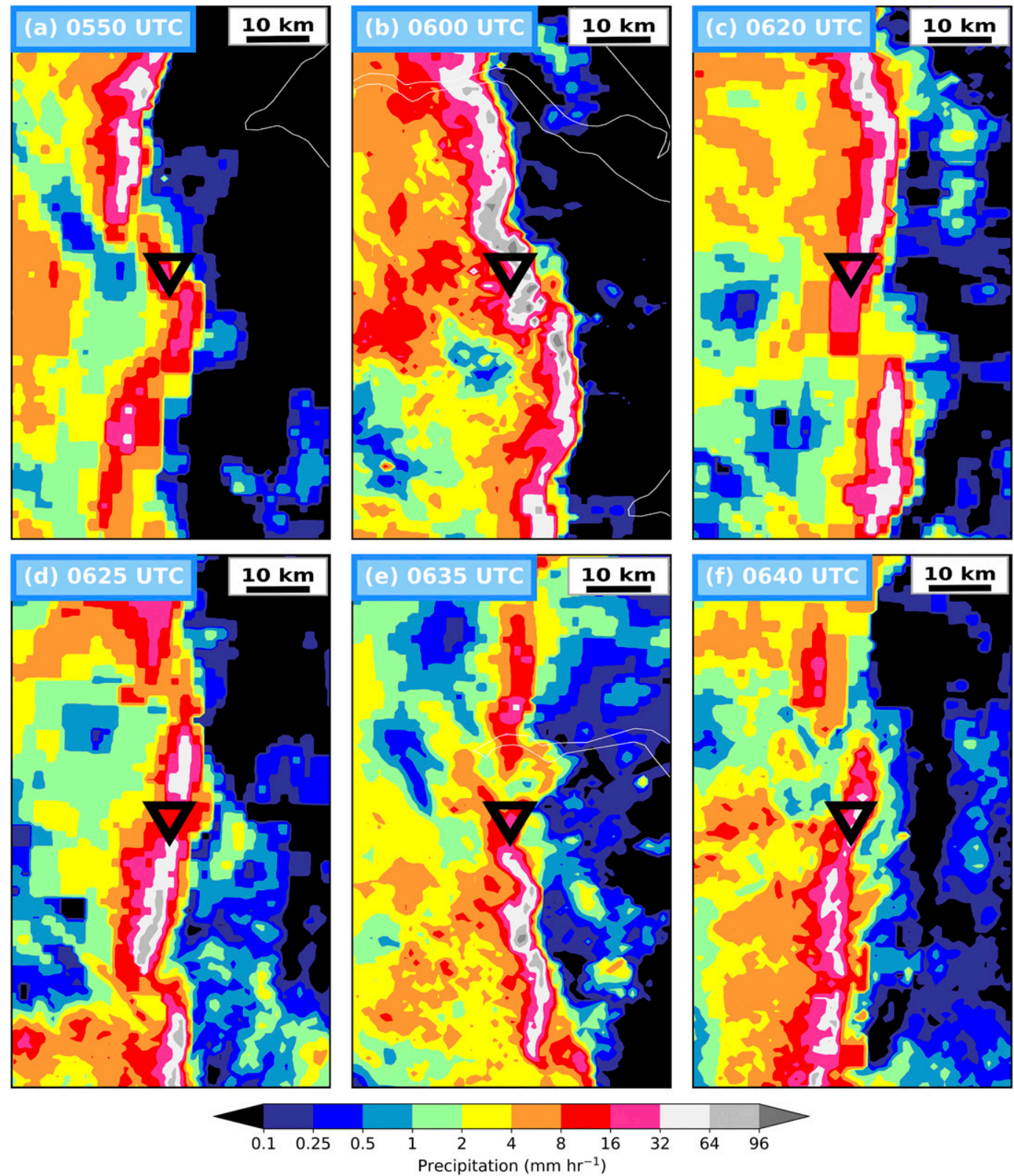

FIG. 6. Radar-derived precipitation rates at the times of six tornado reports (black triangles) of a type 1 QLCS tornado outbreak on 24 Sep 2007.

intense precipitation cores developed within the eastern section of the frontal precipitation. Throughout 0900 UTC and 1000 UTC, the eastern precipitation cores maintained their intensity and structure, but began to decay by 1100 UTC (Figs. 8f-h). By 1200 UTC, all precipitation core structures had dissipated, yet precipitation rates of $>8 \mathrm{~mm} \mathrm{~h}^{-1}$ were still apparent as the front progressed over the southern United Kingdom and the English Channel (Fig. 8i).

Although originally the more intense precipitation structures existed along the western side of the front, these were not associated with tornado reports. All tornado reports occurred after the development of the eastern precipitation cores (Figs. 8f and 9), and none were reported after their dissipation. Four examples of the relationship between precipitation structures and tornado reports are given in Fig. 9. The first two tornado reports occurred shortly after the precipitation cores developed, occurring in close proximity, indicating that both tornado reports may be attributed to the passing of a single precipitation core (e.g., Figs. 9a,b). Similarly, the third and fourth reports also occurred near where 

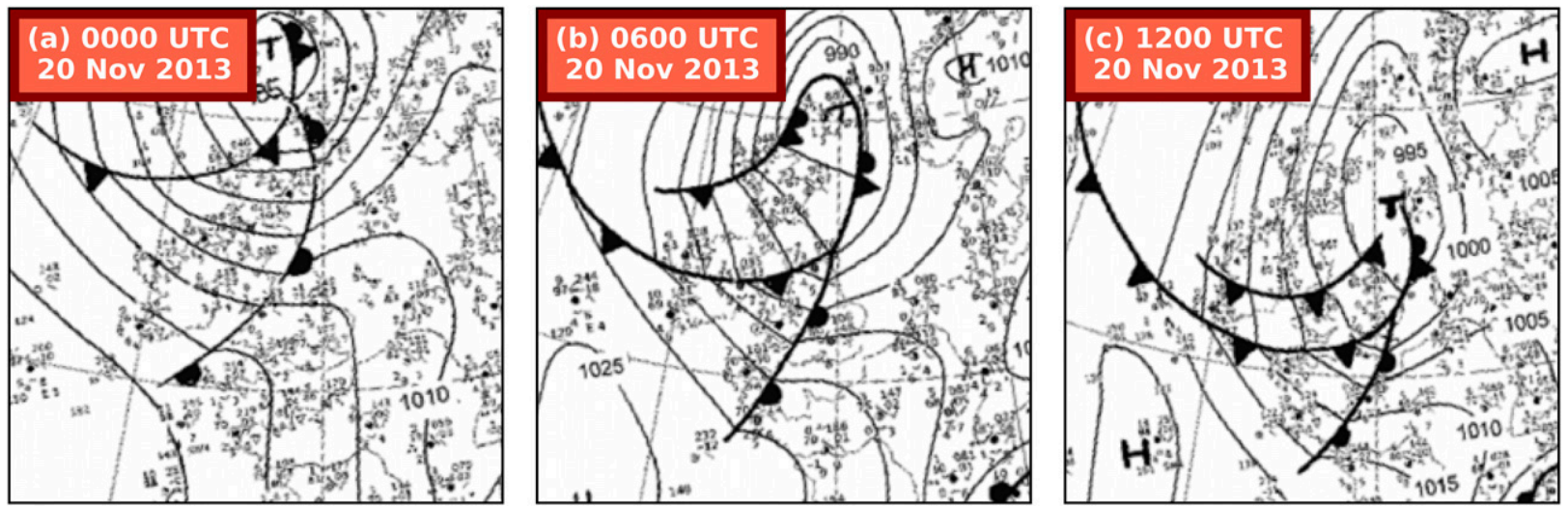

FIG. 7. Surface analysis charts for the passage of a type 2 QLCS tornado outbreak on 20 Nov 2013. [The charts were produced by the Deutscher Wetterdienst (DWD) and are available from http://www1.wetter3.de/archiv/.]

the precipitation cores had started to lose structure and dissipate (e.g., Fig. 9c). Both reports were near to the eastern end of the precipitation cores (e.g., Fig. 9d) and could have been the result of a "tail-end Charlie," or a cell that initiates on the equatorward end of linear convection (https://w1.weather.gov/glossary/ index.php?letter $=$ t, January 2020). Finally, this region of the front was also responsible for the fifth tornado report, which occurred with the rapid intensification of the easternmost precipitation core shortly before dissipation.

\section{Synoptic-scale environments}

To determine the typical synoptic environments for each tornado outbreak type, environments were assessed using the European Centre for Medium-Range Weather Forecasts (ECMWF) ERA5 dataset (Hersbach et al. 2018). Data were available from 1979 to the present at hourly intervals, consisting of 37 vertical pressure levels and a horizontal grid spacing of $0.25^{\circ} \times 0.25^{\circ}$ latitudelongitude. Analysis times were manually assessed as the hour with the most tornado reports. In cases with reports over a several-hour period, the median hour was taken. All five type 1 events and all three type 2 events were analyzed.

\section{a. Mean sea level pressure and upper-level flow}

Figure 10 shows the mean sea level pressure and 500-hPa geopotential heights for all type 1 and type 2 events. For each event, an extratropical cyclone and upper-level trough were near the United Kingdom. However, their locations, movements, and depths differed between types. At the surface in all type 1 events, the center of a deep extratropical cyclone (ranging from 968 to $984 \mathrm{hPa}$ ) was located to the north of the United Kingdom (Figs. 10a,b,d,e,g). Extratropical cyclones in type 2 events were typically shallower (992$996 \mathrm{hPa}$ ) and were located to the northeast of the United Kingdom (Figs. 10c,f,h). All events had identifiable surface troughs coinciding with the location of the surface fronts over the United Kingdom, although type 1 events typically had considerably sharper surface troughs than in type 2 events. Type 1 surface troughs were oriented north-northeast-south-southwest, favoring southerly flow ahead of the surface trough and westerly flow behind, implying a strong cross-frontal wind shift. However, type 2 surface troughs were oriented east-northeastwest-southwest and favored northwesterly flow ahead of the surface trough and northerly flow behind. In all type 1 events, the surface trough was weakly confluent, whereas the surface trough was strongly diffluent in all type 2 events. In all events, there were strong gradients in surface isobars behind the surface trough (Fig. 10).

At $500 \mathrm{hPa}$, a low pressure center was vertically stacked with the surface low with identifiable 500-hPa troughs in all events (Fig. 11). In type 1 events, the 500-hPa trough was oriented meridionally and was located behind, but nearly parallel to, the surface trough (Figs. 11a,b,d,e,g). The surface trough was located under the left/central jet-exit region, typically favoring the cyclonic-shear side. Localized $500-\mathrm{hPa}$ wind speed maxima of $40-50 \mathrm{~m} \mathrm{~s}^{-1}$ were present behind the surface trough but in the base of the 500-hPa trough in all type 1 events except 25 January 2014, where the strongest 500-hPa flow was present behind both the surface and 500-hPa trough and was typically stronger $\left(65 \mathrm{~m} \mathrm{~s}^{-1}\right)$ than all other type 1 events (Fig. 11g). In type 2 events, the 500-hPa trough was nearly parallel to, and vertically stacked with, the surface trough. Localized 500-hPa wind speed maxima of $40-45 \mathrm{~m} \mathrm{~s}^{-1}$ were present behind the surface trough and the diffluent 500-hPa trough (Figs. 11c,f,h). The exception to this was 29 May 2015, where a 500-hPa wind speed maximum of $30-35 \mathrm{~m} \mathrm{~s}^{-1}$ was located behind and in the base of 

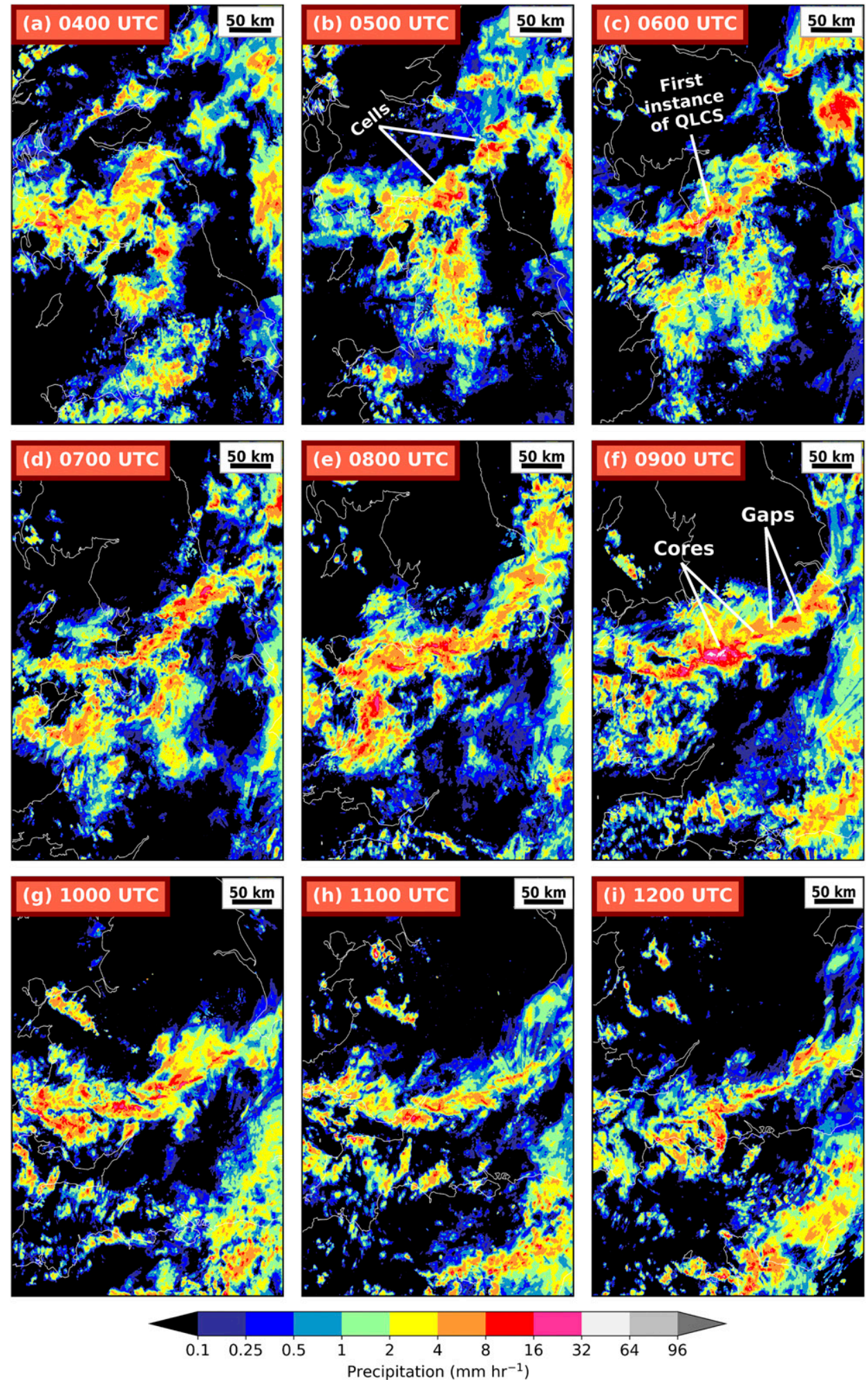

FIG. 8. The evolution of the radar-derived precipitation rate of a type 2 QLCS tornado outbreak on 20 Nov 2013: (a) 0400, (b) 0500, (c) 0600, (d) 0700, (e) 0800, (f) 0900, (g) 1000, (h) 1100, and (i) 1200 UTC. 

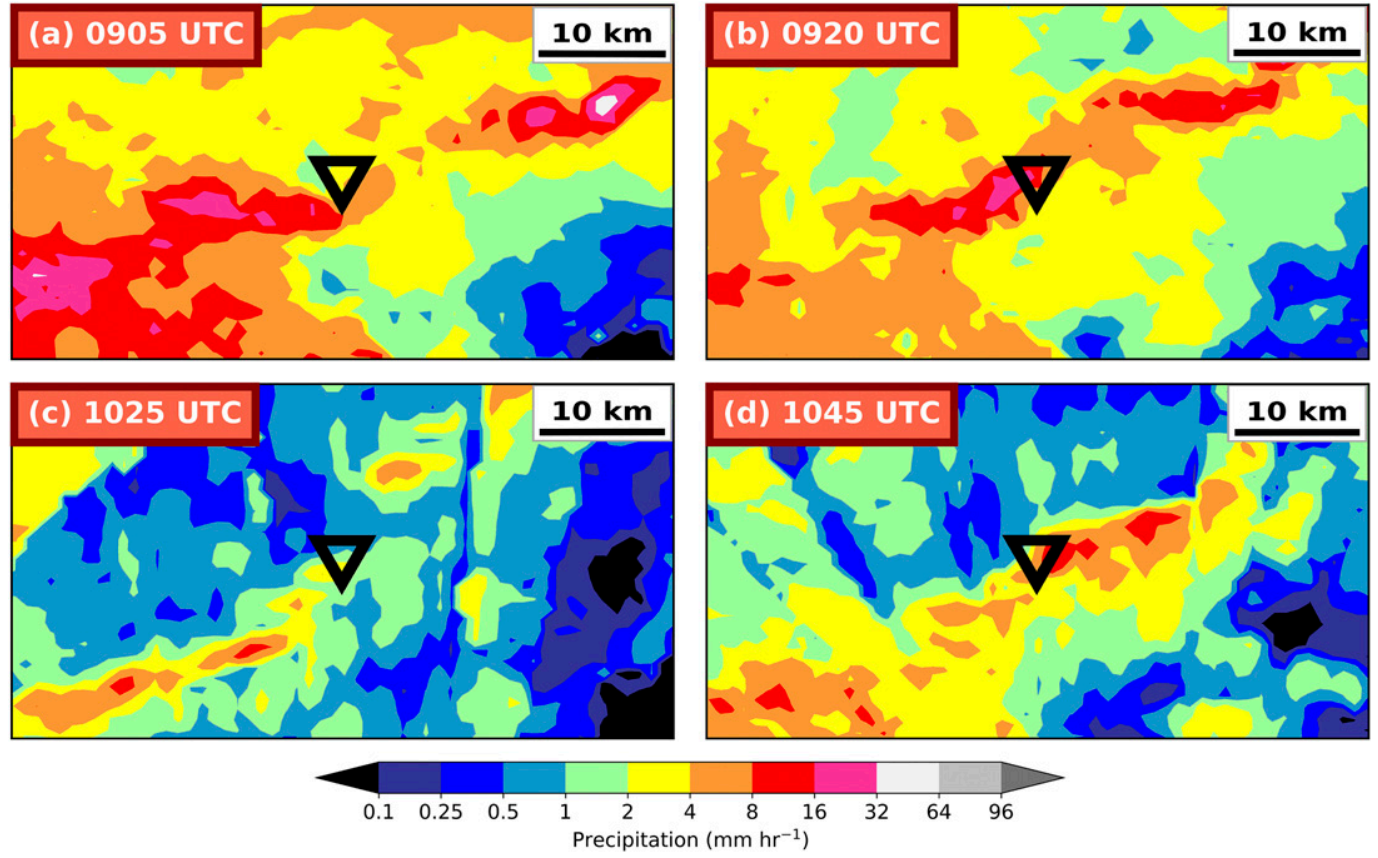

FIG. 9. Radar-derived precipitation rates at the times of four tornado reports (black triangles) of a type 2 QLCS tornado outbreak on 20 Nov 2013.

both the surface and 500-hPa troughs (Fig. 11h). Flow direction was also different. Whereas the other two type 2 events typically had northerly flow at $500 \mathrm{hPa}$, the flow on 29 May 2015 changed from northerly to westsouthwesterly around the location of the surface trough.

There is some similarity between these two types. Specifically, with a $40^{\circ}$ cyclonic rotation of the type 2 $500-\mathrm{hPa}$ trough, the pattern becomes similar to that of type 1 . This may not be surprising because the presence of a 500-hPa trough creates a favorable synoptic environment for ascent and a surface cyclone with front provides the forcing for a quasilinear convective system, these two features being necessary in order to get the tornado outbreak in the first place. As we will show, however, these different synoptic environments appear to bring the other ingredients of instability and moisture together in slightly different ways.

\section{b. Moisture and instability}

Figure 12 shows the 2-m dewpoint temperatures for all events. Both types involved an extension of higher moisture content extending from the Atlantic Ocean ahead of the surface trough. Type 1 events typically favored more moisture being advected into the United Kingdom with higher values of $12^{\circ}-14^{\circ} \mathrm{C}$ (Figs. 12a,b,d,e,g) compared to type 2 events of $6^{\circ}-10^{\circ} \mathrm{C}$ (Figs. 12c,f,h). However, there was some variability among events. For example, in type 1 events, both 27 December 2004 and 25 January 2014 did not advect as high values of moisture ahead of the surface trough in comparison to other type 1 events, perhaps attributing to lower moisture values over the Atlantic Ocean (Figs. 12b,g).

Figure 13 shows the 2-m temperature values for all events. Type 1 events tended to exhibit high prefrontal 2-m temperature compared to postfrontal; however, the magnitudes of cross-frontal 2-m temperature differences varied $\left(2^{\circ}-4^{\circ} \mathrm{C}\right)$ (Figs. 13a,b,d,e,g). All events that had higher values of moisture ahead of the surface trough also had higher prefrontal 2-m temperatures (Figs. 13a,d,e), yet 25 January 2014 also had a distinctive cross-frontal 2-m temperature difference in the southeastern United Kingdom even though prefrontal moisture was lower (Fig. 13g). For 27 December 2004, although there was a clear surface trough extending across the United Kingdom, warm air and moisture advection was limited to the southwestern United Kingdom (Fig. 13b). However, seven of the eight tornado reports associated with that event occurred in the southwestern United Kingdom. Type 2 events had weaker cross-frontal 2-m temperature differences $\left(1^{\circ}-2^{\circ} \mathrm{C}\right)$, once again coinciding with lower values of prefrontal moisture (Figs. 13c,f,h). The variability of moisture and temperature among events does not seem to be associated with seasonal differences. Both types of events typically occurred in autumn and winter with one type 2 event occurring in spring. The differences in temperature and moisture could be associated with the orientation and strength of the surface trough, where strong southerly flow ahead of the surface 

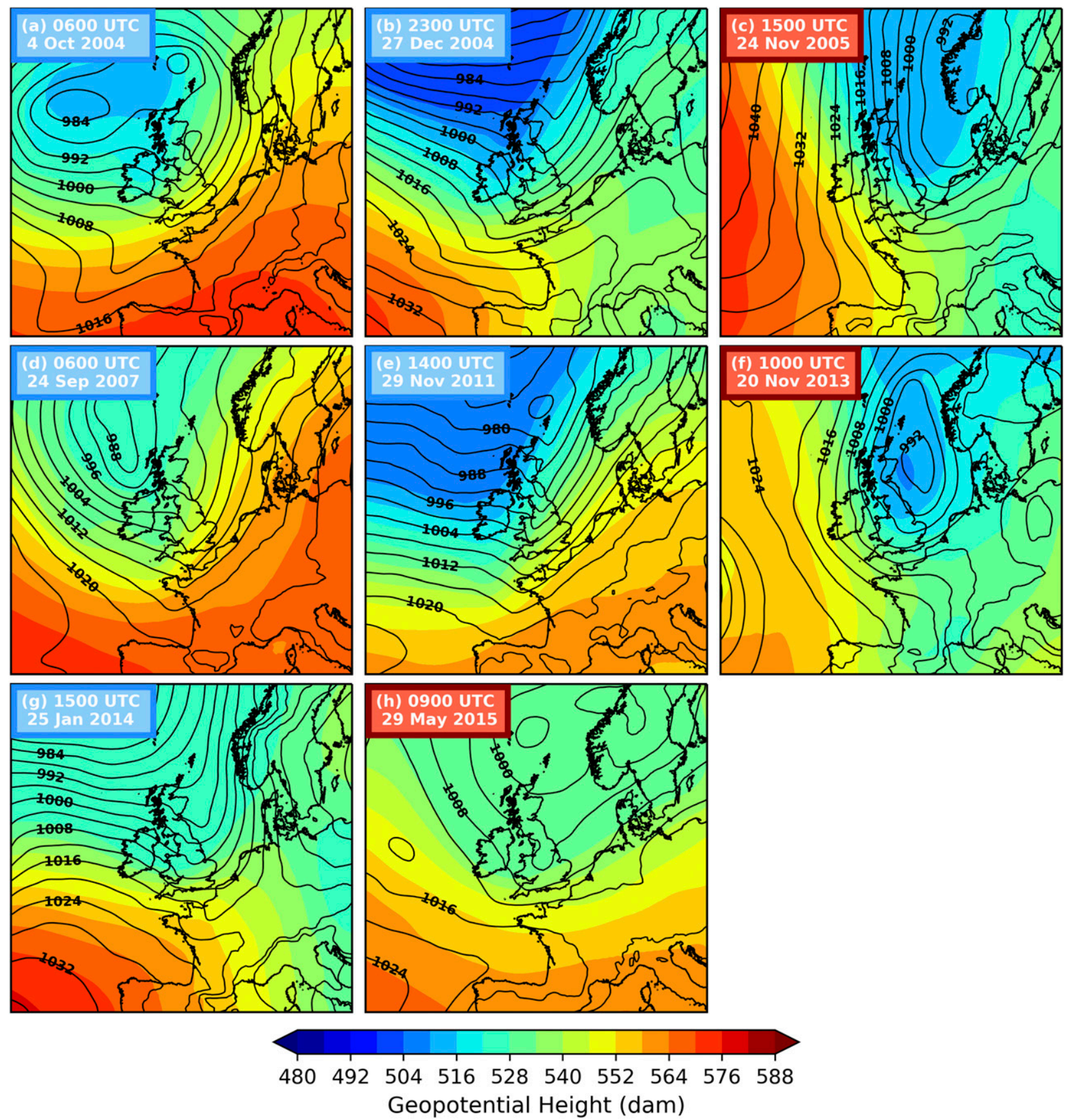

FIG. 10. Mean sea level pressure (contours every $4 \mathrm{hPa}$ ) and 500-hPa geopotential heights (dam; colored, according to scale) for type 1 (blue panel labels) and type 2 (red panel labels) QLCS tornado outbreaks: (a) 0600 UTC 4 Oct 2004, (b) 2300 UTC 27 Dec 2004 , (c) 1500 UTC 24 Nov 2005, (d) 0600 UTC 24 Sep 2007, (e) 1400 UTC 29 Nov 2011, (f) 1000 UTC 20 Nov 2013, (g) 1500 UTC 25 Jan 2014 , and (h) 0900 UTC 29 May 2015.

trough in type 1 events draws warm, moist air from the southern North Atlantic west of Portugal and Spain (Figs. 12a,b,d,e,g and 13a,b,d,e,g). In contrast, weaker, more diffluent flow ahead of the surface trough in type 2 events draws upon cooler air with a more westerly origin over the North Atlantic, hence the lower temperature and moisture values (Figs. 12c,f,h and 13c,f,h).
For instability, prefrontal surface-based CAPE is often considered important for tornadoes in the United Kingdom (e.g., Clark 2013; Apsley et al. 2016). However, CAPE is typically organized within a small corridor extending from the surface trough to only tens of $\mathrm{km}$ ahead (e.g., Apsley et al. 2016). Although the resolution of the reanalysis data may limit the scale and accuracy 

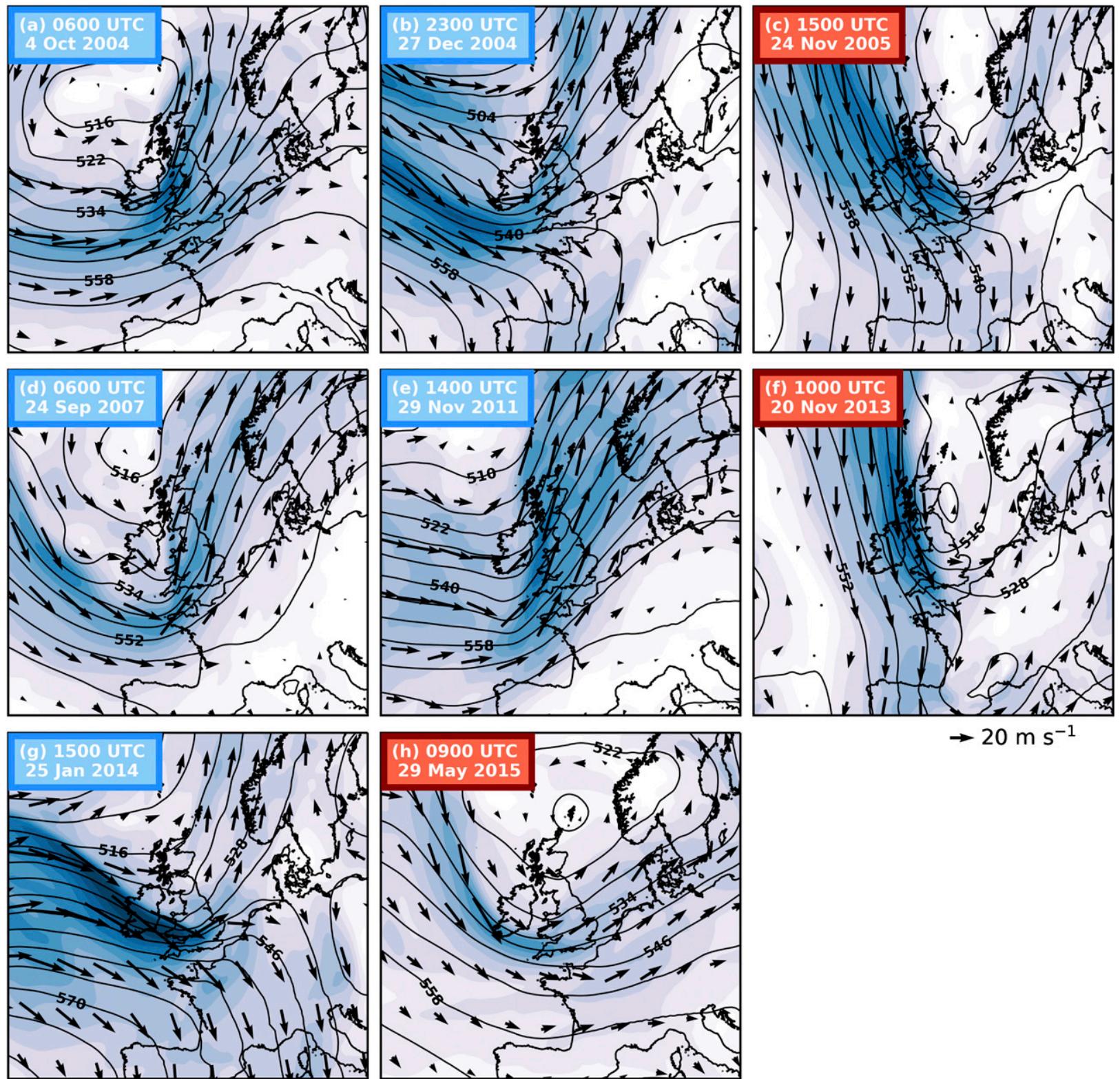

$\rightarrow 20 \mathrm{~m} \mathrm{~s}^{-1}$

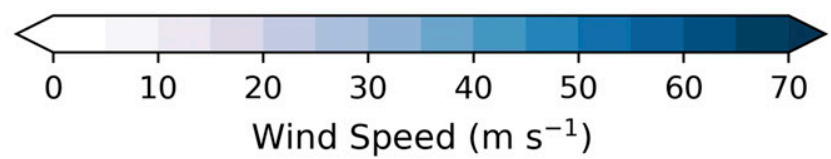

FIG. 11. 500-hPa geopotential height (contours every $6 \mathrm{dam}$ ), wind speed ( $\mathrm{m} \mathrm{s}^{-1}$; colored, according to scale) and wind vectors for type 1 (blue panel labels) and type 2 (red panel labels) QLCS tornado outbreaks: (a) 0600 UTC 4 Oct 2004, (b) 2300 UTC 27 Dec 2004, (c) 1500 UTC 24 Nov 2005, (d) 0600 UTC 24 Sep 2007, (e) 1400 UTC 29 Nov 2011, (f) 1000 UTC 20 Nov 2013, (g) 1500 UTC 25 Jan 2014 , and (h) 0900 UTC 29 May 2015.

of the CAPE, narrow regions of surface-based CAPE $\left(50-150 \mathrm{~J} \mathrm{~kg}^{-1}\right)$ were present ahead of and around the surface trough in all events (Figs. 14a,b,d-h) other than 24 November 2005 where no CAPE was present (Fig. 14c). Type 1 events typically had larger values and greater spatial coverage of CAPE, although there was large variability between cases. For example, CAPE on 24 September 2007 (Fig. 14d) spanned the length of England with local maxima exceeding $200 \mathrm{~J} \mathrm{~kg}^{-1}$, whereas CAPE on 29 November 2011 (Fig. 14e) covered less area 

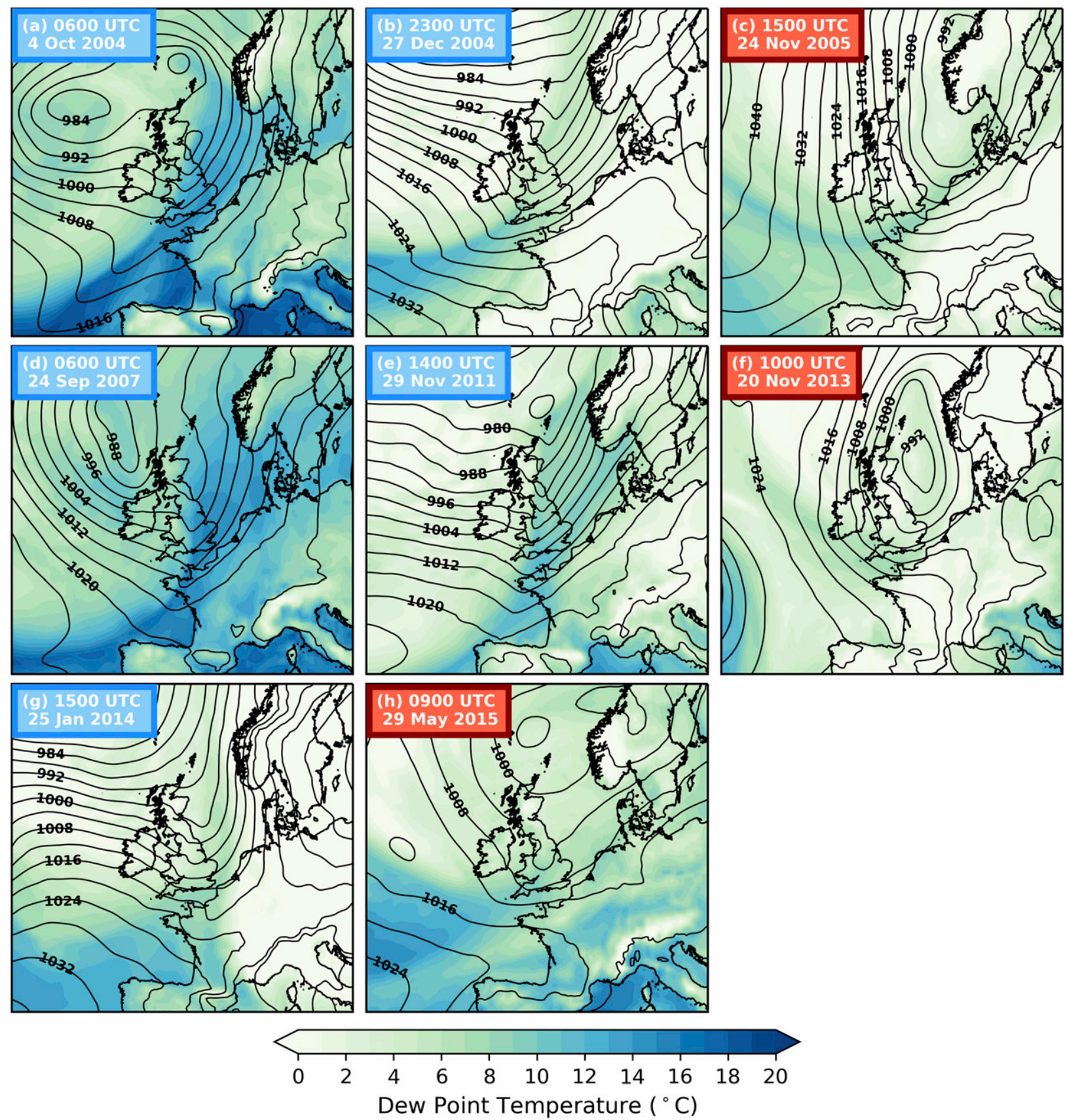

FIG. 12. Mean sea level pressure (contours every $4 \mathrm{hPa}$ ) and 2-m dewpoint temperature $\left({ }^{\circ} \mathrm{C}\right.$; colored, according to scale) for type 1 (blue panel labels) and type 2 (red panel labels) QLCS tornado outbreaks: (a) 0600 UTC 4 Oct 2004, (b) 2300 UTC 27 Dec 2004 , (c) 1500 UTC 24 Nov 2005, (d) 0600 UTC 24 Sep 2007, (e) 1400 UTC 29 Nov 2011, (f) 1000 UTC 20 Nov 2013, (g) 1500 UTC 25 Jan 2014 , and (h) 0900 UTC 29 May 2015.

with smaller maxima of $40-70 \mathrm{~J} \mathrm{~kg}^{-1}$. The lack of a large reservoir of CAPE and the small scale of the CAPE field in the prefrontal environment (e.g., Fig. 13; Apsley et al. 2016), as is often the case in other outbreaks of severe weather in the United States and Europe, may explain why CAPE from proximity soundings may not be a reliable metric by which to distinguish tornadic cases from nontornadic cases in the United Kingdom (e.g., Mulder and Schultz 2015).

\section{c. Bulk shear and low-level flow}

The strength of the prefrontal low-level bulk shear can modulate the formation of vortices within QLCSs, where environments are considered favorable for vortexgenesis 

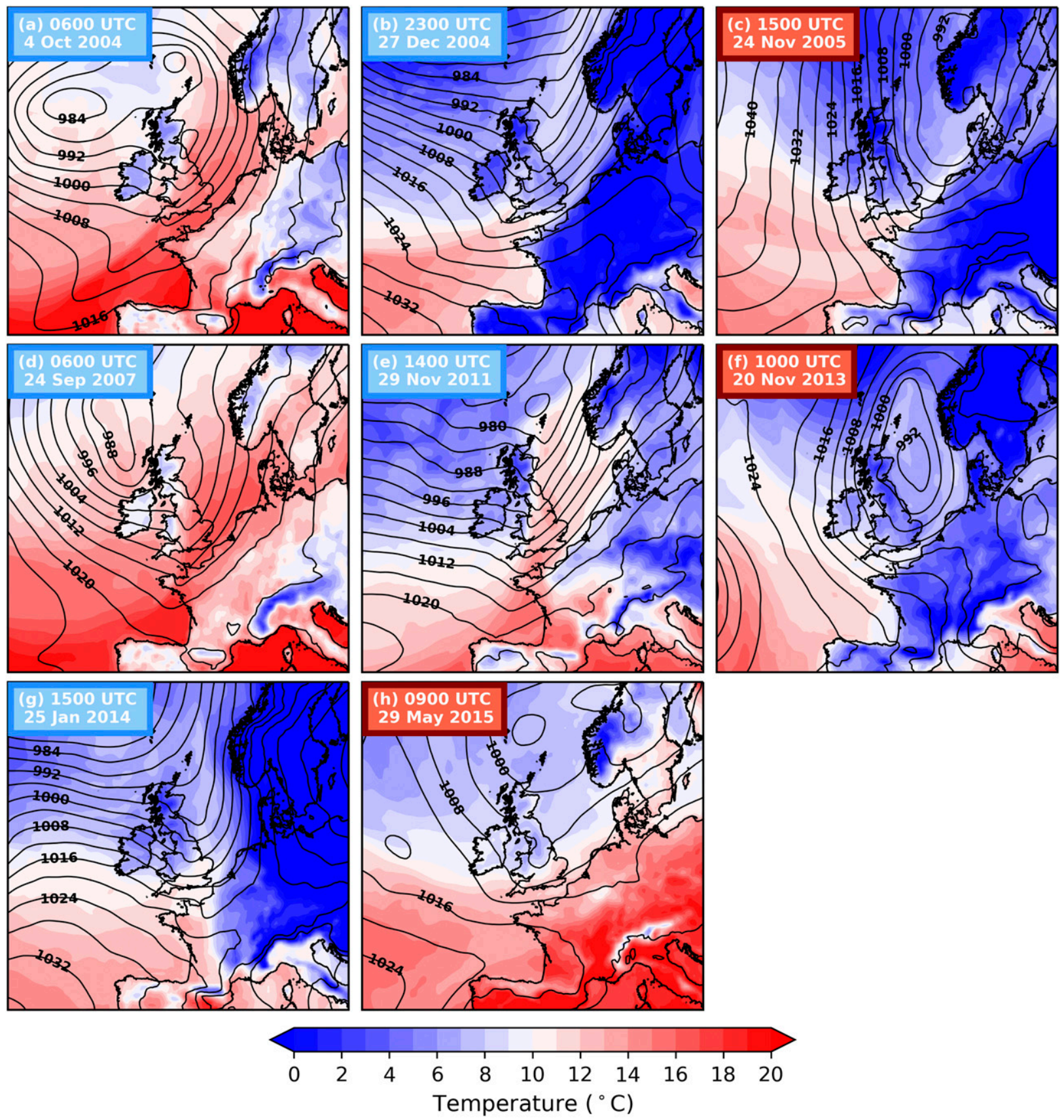

FIG. 13. Mean sea level pressure (contours every $4 \mathrm{hPa}$ ) and $2-\mathrm{m}$ temperature $\left({ }^{\circ} \mathrm{C}\right.$; colored, according to scale) for type 1 (blue panel labels) and type 2 (red panel labels) QLCS tornado outbreaks: (a) 0600 UTC 4 Oct 2004, (b) 2300 UTC 27 Dec 2004, (c) 1500 UTC 24 Nov 2005, (d) 0600 UTC 24 Sep 2007, (e) 1400 UTC 29 Nov 2011, (f) 1000 UTC 20 Nov 2013, (g) 1500 UTC 25 Jan 2014, and (h) 0900 UTC 29 May 2015.

north of the apex of a bowing segment of a convective line if $0-2.5-\mathrm{km}$ bulk shear exceeds $20 \mathrm{~m} \mathrm{~s}^{-1}$ (Weisman and Trapp 2003). However, Clark (2013) found that most of the bulk shear in cool-season narrow cold-frontal rainbands is concentrated in the lowest $1 \mathrm{~km}$, with the mean values of $0-3-\mathrm{km}$ bulk shear only slightly higher than in the $0-1-\mathrm{km}$ layer. Because the reanalysis was available on pressure surfaces, both the low-level $(0-1 \mathrm{~km})$ and midlevel $(0-3 \mathrm{~km})$ bulk-shear composites were approximated by taking the differences between the winds at the surface to $900 \mathrm{hPa}$ and the differences between the winds at the surface to $700 \mathrm{hPa}$, respectively.

Strong low-level bulk shear $\left(15 \mathrm{~m} \mathrm{~s}^{-1}\right)$ was ubiquitous ahead of the surface front and weaker behind in all type 

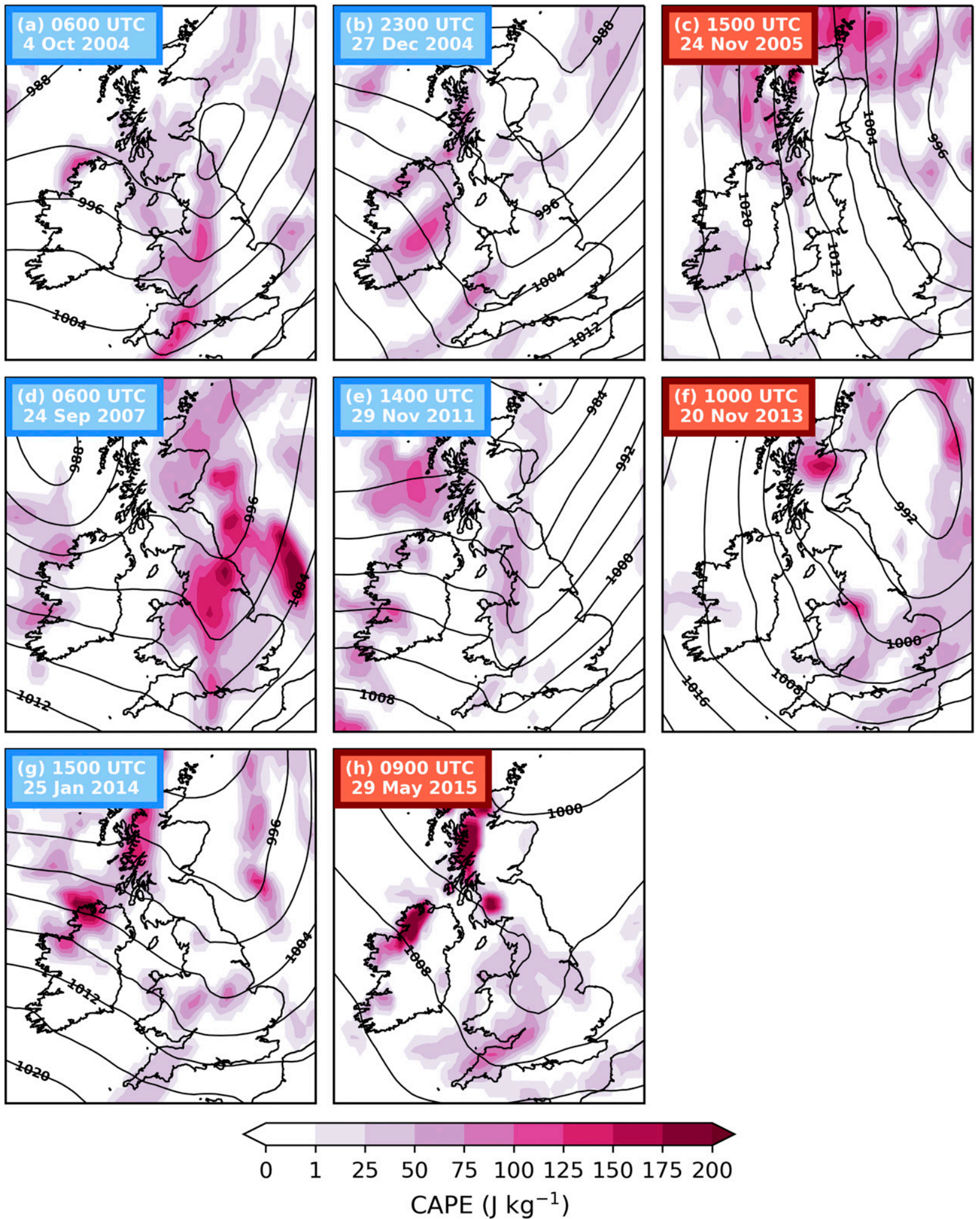

FIG. 14. Mean sea level pressure (contours every $4 \mathrm{hPa})$ and CAPE ( $\mathrm{Jg}^{-1}$; colored, according to scale) for type 1 (blue panel labels) and type 2 (red panel labels) QLCS tornado outbreaks: (a) 0600 UTC 4 Oct 2004, (b) 2300 UTC 27 Dec 2004, (c) 1500 UTC 24 Nov 2005 , (d) 0600 UTC 24 Sep 2007, (e) 1400 UTC 29 Nov 2011, (f) 1000 UTC 20 Nov 2013, (g) 1500 UTC 25 Jan 2014, and (h) 0900 UTC 29 May 2015. 
1 events except 25 January 2014 (Figs. 15a,b,d,e), where strong low-level bulk shear extended behind the surface front over Ireland (Fig. 15g). Shear orientation was also different in this event; whereas all four other type 1 events exhibited shear vectors parallel to the surface front, shear vectors on 25 January 2014 were closer to perpendicular. Type 2 events lacked the prefrontal lowlevel bulk shear as in type 1 events, where instead consistent values of $10 \mathrm{~m} \mathrm{~s}^{-1}$ were present across most of the United Kingdom and shear vectors were perpendicular to the surface front (Figs. 15c,f). The exception was 29 May 2015 (Fig. 15h), where shear was typically weak across the United Kingdom apart from in the location of the surface front $\left(10 \mathrm{~m} \mathrm{~s}^{-1}\right)$. Shear vectors were also closer to parallel to the surface front in this event, similar to type 1 events (Fig. 15h).

A similar pattern can be seen in the $900-\mathrm{hPa}$ flow (Fig. 16). Type 1 events were typified by a low-level jet ahead and parallel to the surface front with wind speeds of $25-30 \mathrm{~m} \mathrm{~s}^{-1}$ (Figs. 16a,b,d,e,g). Flow behind the surface front was close to perpendicular with wind speeds of $10-20 \mathrm{~m} \mathrm{~s}^{-1}$. As with the low-level bulk shear, the exception to this was 25 January 2014; although wind speeds ahead of the surface front were $25 \mathrm{~m} \mathrm{~s}^{-1}$, there was no difference with postfrontal wind speeds (Fig. 16g). Type 2 events lacked a low-level jet ahead of the surface front, where wind speeds were $15 \mathrm{~m} \mathrm{~s}^{-1}$ around the surface front with little difference across the front (Figs. 16c,f,h).

Variations in the midlevel bulk shear were more prominent (Fig. 17). Type 1 events typically had strong midlevel bulk shear $\left(25 \mathrm{~m} \mathrm{~s}^{-1}\right)$, yet the spatial coverage of the shear varied among events. For example, 4 October 2004 had strong midlevel bulk shear ahead and slightly behind the entire surface front (Fig. 17a), yet the strength of 27 December 2004 midlevel bulk shear was weaker ( $15 \mathrm{~m} \mathrm{~s}^{-1}$ compared to $20-25 \mathrm{~m} \mathrm{~s}^{-1}$ ) and confined to the southwestern United Kingdom (Fig. 17b). As with lowlevel bulk shear, 25 January 2014 had strong midlevel bulk shear notable ahead of and behind the surface front (Fig. 17g). Midlevel shear vectors were typically rotated up to $45^{\circ}$ away from the surface front, indicating some low-to-mid-level directional shear. As with low-level bulk shear, type 2 events varied. Midlevel bulk shear of $15 \mathrm{~m} \mathrm{~s}^{-1}$ was present around the surface front on 24 November 2005 and 29 May 2014 (Figs. 17c,h), yet not for 20 November 2013 (Fig. 17f). Directional shear was also not apparent as midlevel bulk shear vectors were typically of a similar orientation to low-level bulk shear vectors. The lack of both a prominent region of prefrontal low-level and midlevel bulk shear, along with the lack of a low-level jet, may be indicative of type 2 events having a reduced ability to generate vortices from the environmental shear.

\section{Precipitation morphology}

Events were classified based on the location of the narrow cold-frontal rainband or linear features within the wider frontal rainband in radar imagery. Four categories were used, adapting the morphologies defined by Parker and Johnson (2000) and Gallus et al. (2008): leading stratiform, trailing stratiform, parallel stratiform, and no stratiform. One limitation of this approach is that QLCSs can exhibit different morphologies during their life cycle. For example, Parsons and Hobbs (1983) noted that narrow cold-frontal rainbands can move differently than the stratiform precipitation, implying QLCSs can transition from one morphology to another. To mitigate this problem, the dominant morphology was used. The dominant morphology was determined by assessing each radar mosaic time that satisfied the QLCS criteria, with the modal morphology taken as dominant. The morphologies around the times of tornado reports was also considered, although in all cases the dominant morphology occurred during this period. Of the five type 1 events, three were classified as trailing stratiform (Figs. 1a,d,g) and two parallel stratiform (Figs. 1b,e), whereas the three type 2 events were classified as two parallel stratiform (Figs. 1f,i) and one no stratiform (Fig. 1c). Precipitation core-and-gap structures occurred in both type 1 and type 2 events, although there were differences in intensity, wavelength, and duration of the structures between types (Fig. 1, white boxes). The differences in the narrow cold-frontal rainband and core-and-gap structures are discussed in the next paragraphs.

In all five type 1 events, narrow cold-frontal rainbands initially formed as the front moved over the Irish Sea. During the passage over the Irish Sea, the narrow coldfrontal rainband was typically linear with no signs of coreand-gap structures, as is illustrated by the 24 September 2007 event (Fig. 5a). As the line moved onto the west coast of the United Kingdom, the narrow cold-frontal rainband typically fractured and developed into wavelike structures with wavelengths (distance between the centers of precipitation maxima along the apices of the waves) of approximately $50 \mathrm{~km}$ (Figs. $5 \mathrm{c}$,d).

As the narrow cold-frontal rainband moved inland, precipitation intensity tended to increase as the wavelike structures formed into well-defined core-and-gap structures (Fig. 5f). Precipitation cores in type 1 events generally had intense precipitation rates associated with them, reaching $32-64 \mathrm{~mm} \mathrm{~h}^{-1}$ and locally higher. Precipitation gaps were not as consistent, with some being completely precipitation free and others producing precipitation rates of $16 \mathrm{~mm} \mathrm{~h}^{-1}$. Cores typically had wavelengths (distance between precipitation core centers) of $30-40 \mathrm{~km}$ 

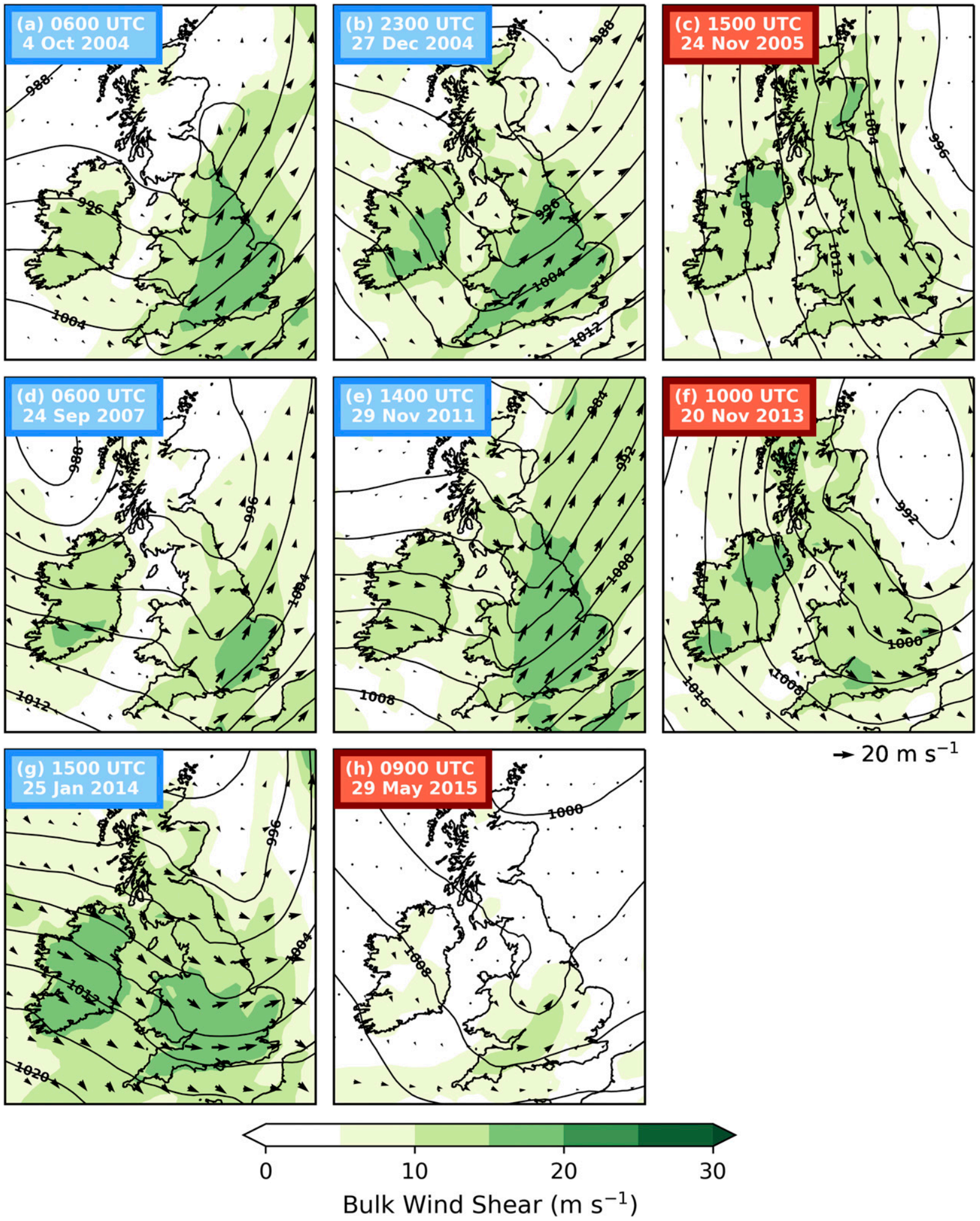

FIG. 15. Mean sea level pressure (contours every $4 \mathrm{hPa}$ ), surface- $900-\mathrm{hPa}\left(0-1-\mathrm{km}\right.$ proxy) bulk shear ( $\mathrm{m} \mathrm{s}^{-1}$; colored, according to scale) and directional shear vectors for type 1 (blue panel labels) and type 2 (red panel labels) QLCS tornado outbreaks: (a) 0600 UTC 4 Oct 2004, (b) 2300 UTC 27 Dec 2004, (c) 1500 UTC 24 Nov 2005, (d) 0600 UTC 24 Sep 2007, (e) 1400 UTC 29 Nov 2011, (f) 1000 UTC 20 Nov 2013, (g) 1500 UTC 25 Jan 2014, and (h) 0900 UTC 29 May 2015. 

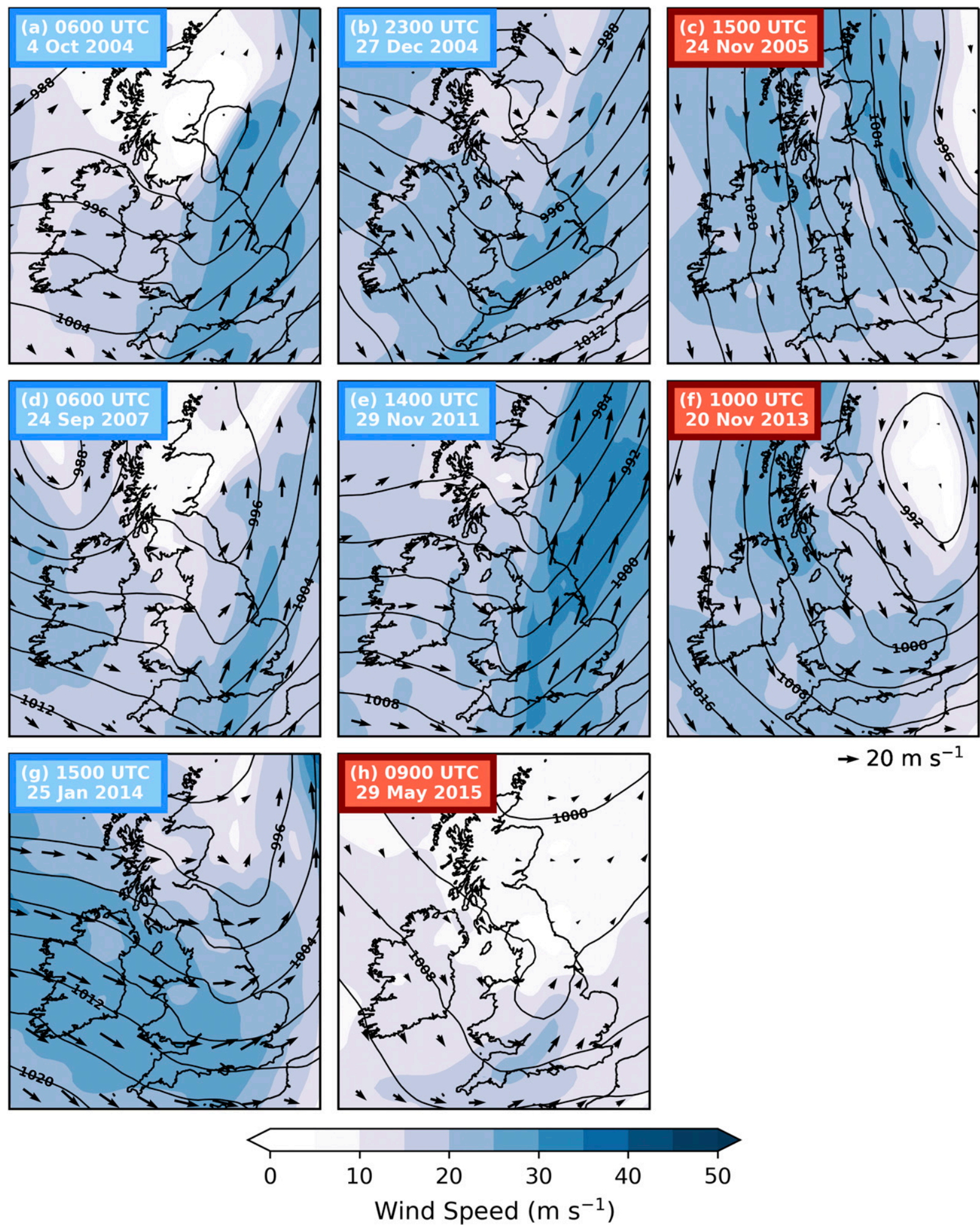

FIG. 16. Mean sea level pressure (contours every $4 \mathrm{hPa}$ ), $900-\mathrm{hPa}$ wind speed ( $\mathrm{m} \mathrm{s}^{-1}$; colored, according to scale) and wind vectors for type 1 (blue panel labels) and type 2 (red panel labels) QLCS tornado outbreaks: (a) 0600 UTC 4 Oct 2004, (b) 2300 UTC 27 Dec 2004 , (c) 1500 UTC 24 Nov 2005, (d) 0600 UTC 24 Sep 2007, (e) 1400 UTC 29 Nov 2011, (f) 1000 UTC 20 Nov 2013, (g) 1500 UTC 25 Jan 2014, and (h) 0900 UTC 29 May 2015. 

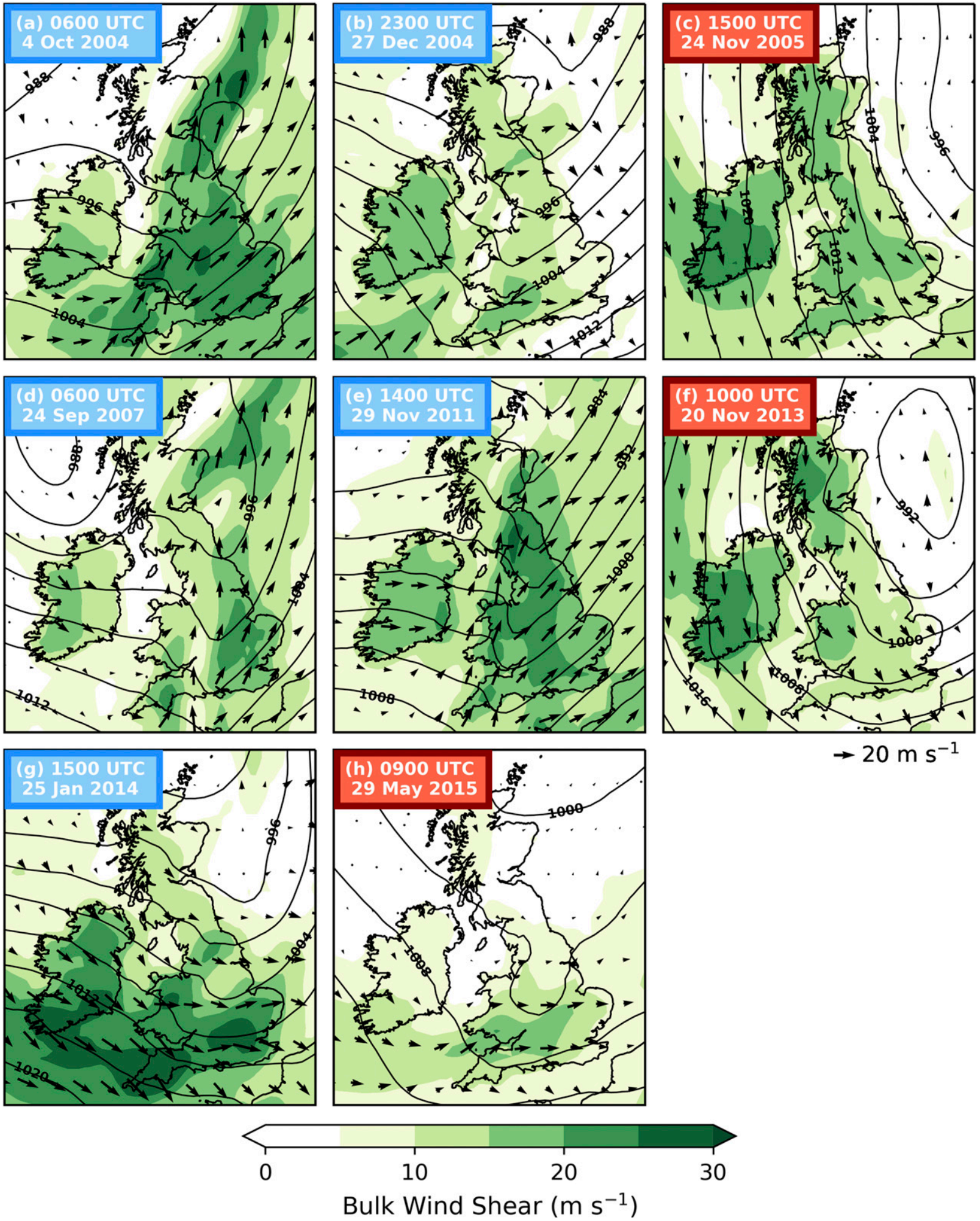

FIG. 17. Mean sea level pressure (contours every $4 \mathrm{hPa}$ ), surface- $700-\mathrm{hPa}\left(0-3-\mathrm{km}\right.$ proxy) bulk shear ( $\mathrm{m} \mathrm{s}^{-1}$; colored, according to scale) and directional shear vectors for type 1 (blue panel labels) and type 2 (red panel labels) QLCS tornado outbreaks: (a) 0600 UTC 4 Oct 2004, (b) 2300 UTC 27 Dec 2004, (c) 1500 UTC 24 Nov 2005, (d) 0600 UTC 24 Sep 2007, (e) 1400 UTC 29 Nov 2011, (f) 1000 UTC 20 Nov 2013, (g) 1500 UTC 25 Jan 2014, and (h) 0900 UTC 29 May 2015. 


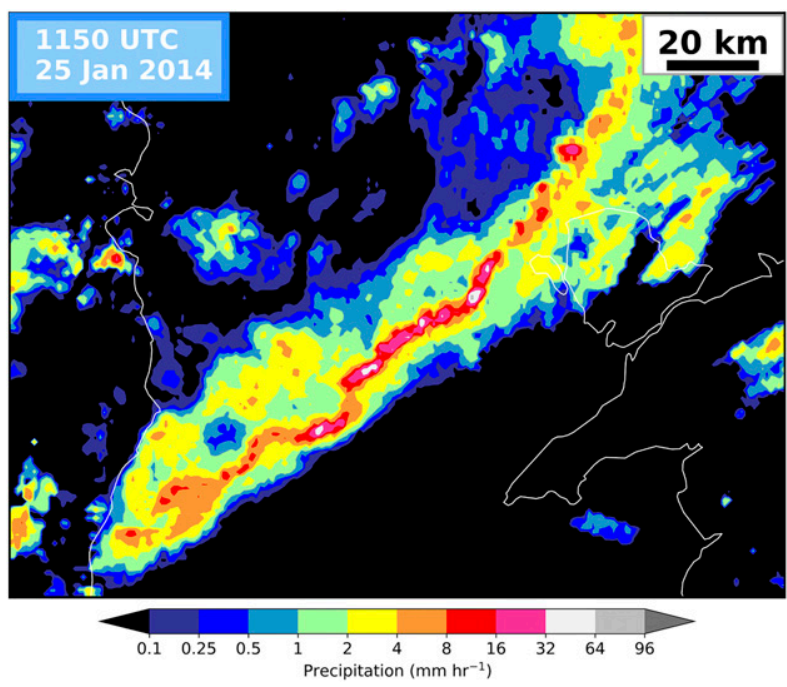

FIG. 18. Radar-derived precipitation rate at 1150 UTC 25 Jan 2014 for a type 1 QLCS producing precipitation-core structures over the Irish Sea.

and were rotated up to $30^{\circ}$ clockwise to the orientation of the front.

Precipitation intensity decreased and cores-and-gaps lost structure as the front approached the North Sea/English Channel (Fig. 5h), where precipitation-core merging occurred in four of the five type 1 cases as the wavelengths of the cores increased (sometimes $>100 \mathrm{~km}$ ) before dissipating (Fig. 5i). The exception to this was 25 January 2014, where core-and-gap structures were apparent on radar over the Irish Sea shortly after the development of the narrow cold-frontal rainband and long before the front moved onshore (Fig. 18). Furthermore, the event on 25 January 2014 did not display merging; instead, core-and-gap structures occurred as the front progressed into the English Channel (not shown). In fact, the system was still maintaining the narrow cold-frontal rainband as it progressed into northern France before moving out of range of U.K. radars. ${ }^{1}$ A simplified schematic for the evolution of precipitation core-and-gap structures in type 1 events is given in Fig. 19.

All three type 2 events did not produce narrow coldfrontal rainbands prior to precipitation core development,

\footnotetext{
${ }^{1}$ In response to a reviewer comment, the linearity of radar signatures as the narrow cold-frontal rainbands progressed over the Irish Sea was not a consequence of radar beam heights failing to capture the shallow nature of the core-and-gap structures. The core-and-gap structures are typically several kilometers in depth (e.g., James and Browning 1979; Matejka et al. 1980; Carbone 1982; Locatelli et al. 1995; Smart and Browning 2009), hence, would be detectable by near-coastal radars in the western United Kingdom long before the narrow cold-frontal rainband approached the shore.
}
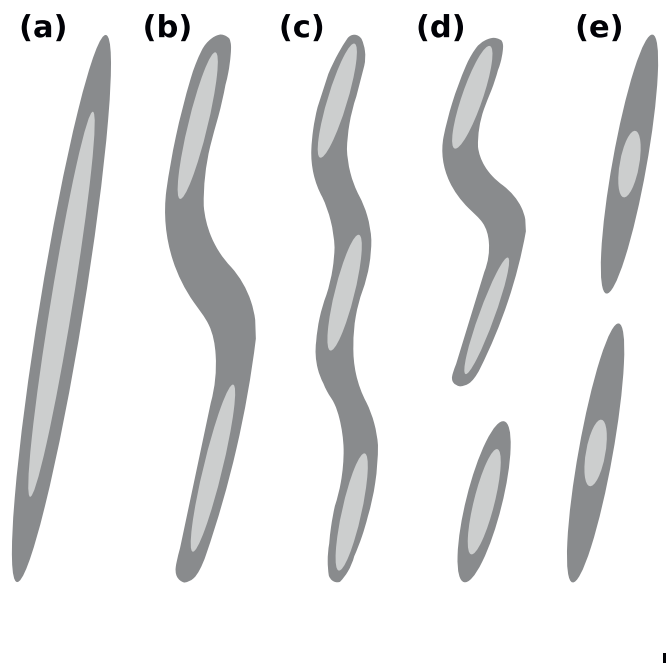

(f)

FIG. 19. Simplified schematic snapshots of the evolution of precipitation rate (grays) of a type 1 QLCS tornado outbreak: (a) narrow cold-frontal rainband, (b) fracture in the narrow cold-frontal rainband, (c) wavelike feature with core-and-gap structures, (d) equally spaced core-and-gap structures, (e) elongated cores, and (f) decay. The scale bar represents the typical horizontal distance within each panel, not the implied distance between panels.

as is illustrated by the 20 November 2013 event (Figs. 8a-e). Instead, sporadic precipitation cores formed within the associated wider frontal rainband (Figs. 8f,g). Precipitation cores in type 2 events reached intensities of up to $8 \mathrm{~mm} \mathrm{~h}^{-1}$ and locally higher, being weaker than in type 1 events. Core structures typically had wavelengths of $50 \mathrm{~km}$, yet due to their sporadic nature, wavelengths varied between events. In all type 2 events, there was no evidence of precipitation-core merging. Instead, precipitation cores became elongated before dissipating and became indistinguishable from the wider frontal rainband as the QLCS moved into the English Channel (Figs. 8h,i). A simplified schematic for the typical evolution of precipitation coreand-gap structures in type 2 events is given in Fig. 20.

As type 2 events tended to move southward from Scotland into England, there was no relationship between the development of wavelike structures and subsequently precipitation cores from QLCSs moving onshore, with only one of the three cases producing coreand-gap structures in this manner. This case occurred on 29 May 2015, where the frontal passage developed irregular core-and-gap structures as it made landfall onto southwest United Kingdom (Fig. 21). Upon landfall, the precipitation cores intensified and became more organized in a similar manner to type 1 events.

To illustrate the relationship between the formation of the linear convection, core-and-gap structure, and tornado occurrence, Fig. 22 displays the timelines of the evolutions of the nine QLCS tornado outbreaks. In type 
(a)

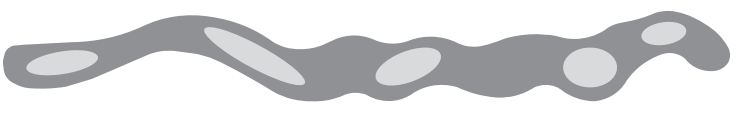

(b)

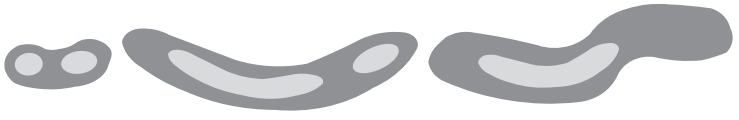

(c)
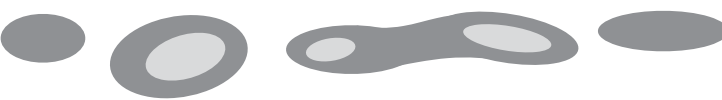

(d)

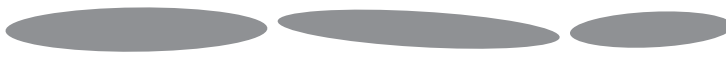

$50 \mathrm{~km}$

FIG. 20. Simplified schematic snapshots of the evolution of precipitation (grays) of a type 2 QLCS tornado outbreak: (a) poorly organized frontal precipitation, (b) wavelike structures, (c) sporadic core-and-gap structures, and (d) decay. The scale bar represents the typical horizontal distance within each panel, not the implied distance between panels.

1 events, the start of the QLCS was defined as the first instance of a narrow cold-frontal rainband on radar mosaics. However, as type 2 events did not produce well-defined narrow cold-frontal rainbands, the first instance of the QLCS was defined as the time when sporadic precipitation maxima of $>8 \mathrm{~mm} \mathrm{~h}^{-1}$ spanned the width of the wide frontal rainband (e.g., Fig. 8d). The occurrence of cores was defined as the times when the first precipitation cores were observed until the precipitation cores became either indistinguishable from the wide frontal rainband or dissipated entirely. In both types, cores developed approximately $1-2 \mathrm{~h}$ after the start of the QLCS (Fig. 22, orange bars), with the exception of 25 January 2014, which displayed cores about $15 \mathrm{~min}$ after the development of the narrow cold-frontal rainband. Each of the nine events had a well-defined period where cores were apparent on radar mosaics. Tornado reports typically occurred in type 1 events two or more hours after the first development of core-and-gap structures, with some events exhibiting cores for over $4 \mathrm{~h}$ before tornado reports (Fig. 22, type 1). Conversely, type 2 tornado reports tended to occur less than $1 \mathrm{~h}$ after the development of cores (Fig. 22, type 2). Thus, type 1 events took longer to reach tornadogenesis than type 2 events.

However, both the type 2 case of 29 May 2015 and the unassigned case of 10 August 2014 did not display well-defined regions of core-and-gap structures, prior to tornado reports. This difference may be a consequence of different temporal intervals for tornado reports and radar mosaics ( $1 \mathrm{~h}$ and $5 \mathrm{~min}$, respectively). As type 2 events typically produced tornadoes less than $1 \mathrm{~h}$ after core-andgap development, that tornado reports were rounded to the
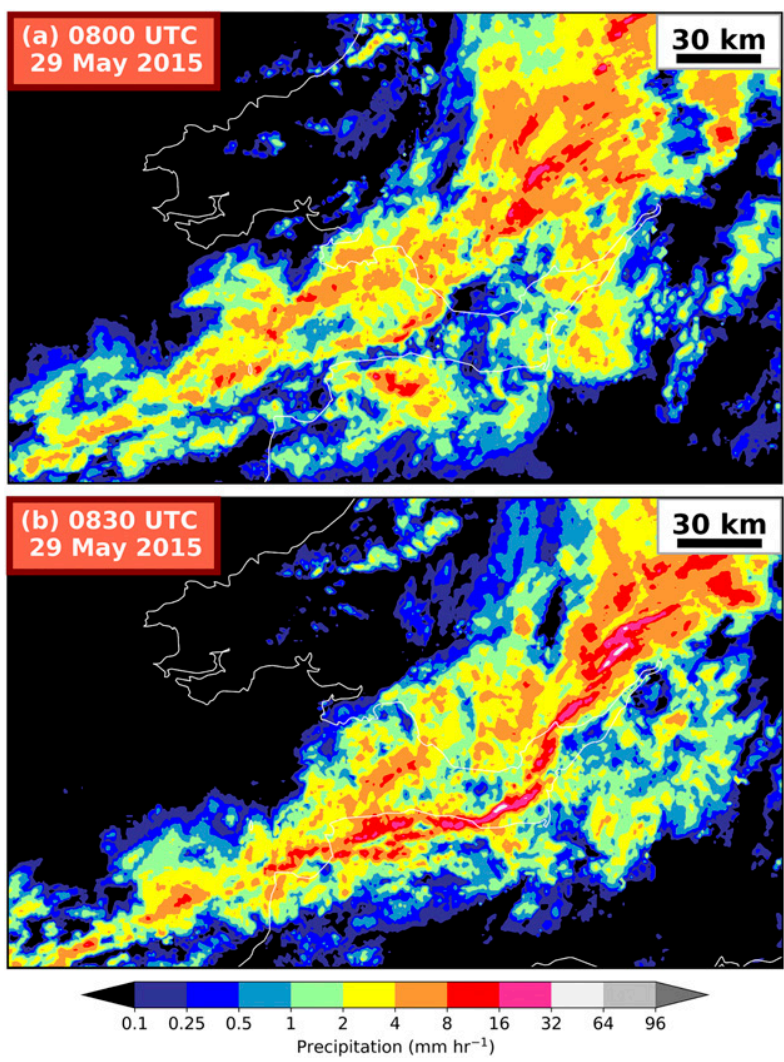

FIG. 21. The evolution of the radar-derived precipitation rate of a type 2 QLCS tornado outbreak on 29 May 2015: (a) 0800 UTC with no core-and-gap structure before moving onshore and (b) 0830 UTC with core-and-gap structure shortly after making landfall.

nearest hour may have distorted the relationship between core-and-gap development and tornado times. The same issue can be applied to 24 November 2005, where Fig. 22 implies that core-and-gap structures and tornado report times ended at either the same time or tornado reports continued beyond core-and-gap observations. Furthermore, both the periods of both core-and-gap structures and QLCS ended abruptly in the 25 January 2014 event (Fig. 22). The sudden ending of the event was due to the storm moving out of the U.K. radar domain; hence, the cutoff time was the final instance the event appeared on radar.

\section{Summary}

Nine tornado outbreaks in the United Kingdom were documented during the 16-yr period 2004-19. Of the nine, eight have been classified into two synoptic-scale environments: type 1 and type 2 . The synoptic-scale environments for both types was examined using ERA5 reanalysis data and a manual assessment of precipitation morphologies using radar mosaics. The following are the main findings. 


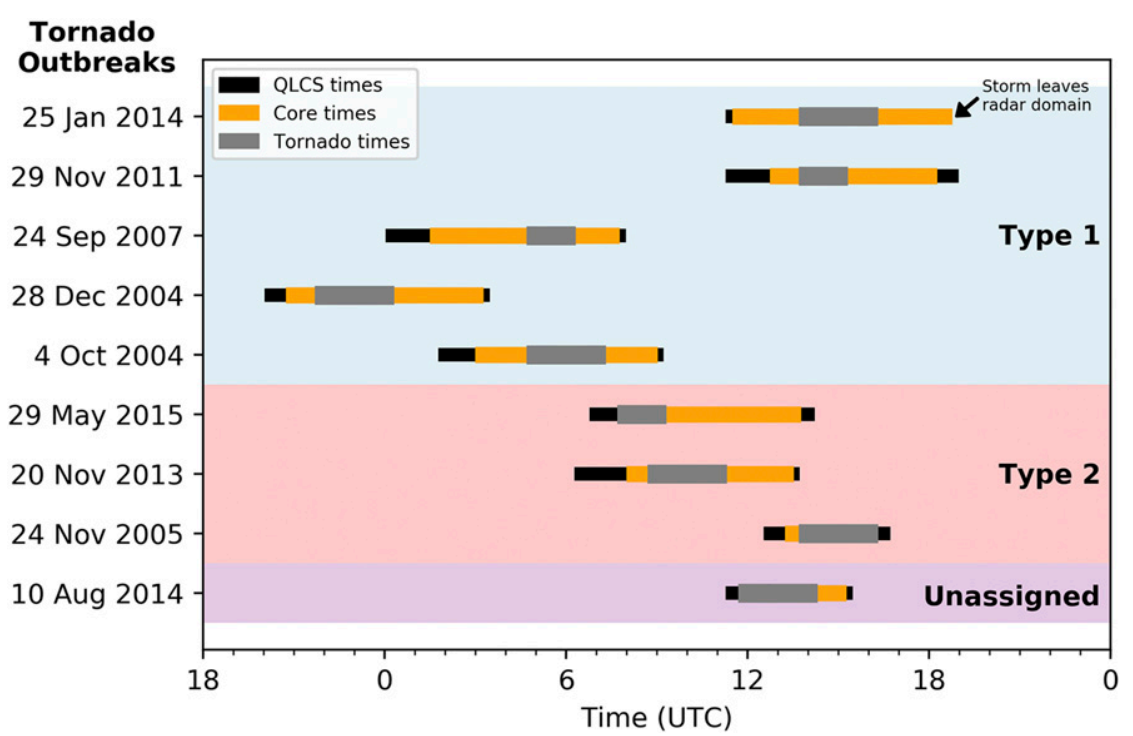

FIG. 22. Timelines of each QLCS tornado outbreak event, indicating the time periods of the QLCS (black bar), precipitation cores that develop within the QLCS (orange bar) and tornado reports associated with each event (gray bar).

Type 1 events were characterized by a meridionally oriented surface trough collocated with a cold front, with fronts extending from an extratropical cyclone located to the north of the United Kingdom moving from west to east. Conversely, type 2 events were characterized by a zonally oriented surface trough collocated with a cold or occluded front, with fronts extending from an extratropical cyclone located to the northeast of the United Kingdom/Scandinavia moving from north to south. The low centers of each type were vertically stacked from the surface to a 500-hPa trough.

Analyses of moisture and instability for both types shows the ingredients for convection were present in all cases except 24 November 2005. However, type 1 environments had higher prefrontal moisture (2-m dewpoint temperatures of $12^{\circ}-14^{\circ} \mathrm{C}$ compared to $6^{\circ}-10^{\circ} \mathrm{C}$ ) and generally slightly higher values of CAPE (exceeding $200 \mathrm{~J} \mathrm{~kg}^{-1}$ locally), although small values of CAPE ahead and around the surface trough were present in all cases (except 24 November 2005). Given the small degree of instability, such narrow cold-frontal rainbands over the United Kingdom may be similar to such features observed elsewhere in similar environments (e.g., James and Browning 1979; Matejka et al. 1980; Carbone 1982; Locatelli et al. 1995).

The development of narrow cold-frontal rainbands and subsequent precipitation core-and-gap structures only occurred in type 1 events. However, type 2 events developed precipitation maxima of about $16 \mathrm{~mm} \mathrm{~h}^{-1}$ spanning the width of the wide frontal rainband, which evolved into sporadic precipitation cores. Although only speculative, differences in low-level and midlevel bulk shear values may have influenced the organization of precipitation structures. Type 1 events typically had prefrontal $0-1-\mathrm{km}$ and $0-3-\mathrm{km}$ bulk shear of 15 and 20-25 m s${ }^{-1}$, respectively, whereas type 2 events had lower values of 10 and $15 \mathrm{~m} \mathrm{~s}^{-1}$, respectively. Stronger low- and midlevel bulk shear, along with stronger lowlevel convergence due to the sharper trough and front, may explain why type 1 events developed narrow coldfrontal rainbands that eventually broke down into semiconsistently spaced core-and-gap structures, as has been discussed by Clark and Parker (2014).

All tornado reports occurred when precipitation cores were apparent on radar mosaics. However, type 1 events displayed core-and-gap structures for $2-4 \mathrm{~h}$ prior to tornado reports, whereas type 2 events displayed precipitation cores for an hour or less prior to tornadoes. Although both events produced tornadoes over a relatively short time period (1-3h), type 2 events reaching tornadogenesis faster than in type 1 events suggests potential differences in tornadogenesis processes between the two types.

Acknowledgments. We thank David Smart and two anonymous reviewers for their comments that have improved this article. We thank Prof. Geraint Vaughan of the University of Manchester and Trevor Mitchell for informative discussions regarding the manuscript. We also thank TORRO for providing access to the database of tornado reports and the British Atmospheric Data Centre and the Met Office for providing access to 
radar data. Buckingham is funded by the National Environmental Research Council's Understanding the Earth, Atmosphere, and Ocean Doctoral Training Programme, Grant NE/L002469/1. Schultz is partially funded by the Natural Environment Research Council through Grant NE/N003918/1.

\section{REFERENCES}

Antonescu, B., G. Vaughan, and D. M. Schultz, 2013: A five-year radar-based climatology of tropopause folds and deep convection over Wales, United Kingdom. Mon. Wea. Rev., 141, 1693-1707, https://doi.org/10.1175/MWR-D-12-00246.1.

Apsley, M. L., K. J. Mulder, and D. M. Schultz, 2016: Reexamining the United Kingdom's greatest tornado outbreak: Forecasting the limited extent of tornadoes along a cold front. Wea. Forecasting, 31, 853-875, https://doi.org/10.1175/WAF-D-15-0131.1.

Ashley, W. S., A. M. Haberlie, and J. Strohm, 2019: A climatology of quasi-linear convective systems and their hazards in the United States. Wea. Forecasting, 34, 1605-1631, https://doi.org/10.1175/ WAF-D-19-0014.1.

Brooks, H., and C. A. Doswell, 2001: Some aspects of the international climatology of tornadoes by damage classification. Atmos. Res., 56, 191-201, https://doi.org/10.1016/S0169-8095(00)00098-3.

Burke, P. C., and D. M. Schultz, 2004: A 4-yr climatology of coldseason bow echoes over the continental United States. Wea. Forecasting, 19, 1061-1074, https://doi.org/10.1175/811.1.

Carbone, R. E., 1982: A severe frontal rainband. Part I: Stormwide hydrodynamic structure. J. Atmos. Sci., 39, 258-279, https:// doi.org/10.1175/1520-0469(1982)039<0258:ASFRPI>2.0.CO;2.

Clark, M. R., 2011: Doppler radar observations of mesovortices within a cool-season tornadic squall line over the UK. Atmos. Res., 100, 749-764, https://doi.org/10.1016/j.atmosres.2010.09.007.

_ 2013: A provisional climatology of cool-season convective lines in the UK. Atmos. Res., 123, 180-196, https://doi.org/ 10.1016/j.atmosres.2012.09.018.

— wind and pressure fields near tornadic and nontornadic cold fronts. Mon. Wea. Rev., 142, 3560-3585, https://doi.org/10.1175/ MWR-D-13-00395.1.

—_ and D. J. Smart, 2016: Supercell and non-supercell tornadoes in the United Kingdom and Ireland. Extreme Weather: Forty Years of the Tornado and Storm Research Organisation (TORRO), R. K. Doe, Ed., Wiley Blackwell, 31-60.

Davis, J. M., and M. D. Parker, 2014: Radar climatology of tornadic and nontornadic vortices in high-shear, low-CAPE environments in the Mid-Atlantic and southeastern United States. Wea. Forecasting, 29, 828-853, https://doi.org/10.1175/ WAF-D-13-00127.1.

Doswell, C. A., 1991: Mesoscale convective patterns of the southern high plains. Bull. Amer. Meteor. Soc., 72, 389-390, https://doi.org/ 10.1175/1520-0477(1990)071<0994:MCPOTS>2.0.CO;2.

— H. E. Brooks, and N. Dotzek, 2009: On the implementation of the enhanced Fujita scale in the USA. Atmos. Res., 93, 554-563, https://doi.org/10.1016/j.atmosres.2008.11.003.

Elsom, D. M., 1984: Spatial and temporal distributions of tornadoes in the United Kingdom 1960-1982. J. Meteor., 10, 203-211.

_ 1985: Tornadoes formed in association with cold front: The example of the outbreak of 21 tornadoes on 8 February 1984. J. Meteor., 10, 4-15.

— , G. T. Meaden, D. J. Reynolds, M. W. Rowe, and J. D. Webb, 2001: Advances in tornado and storm research in the United
Kingdom and Europe: The role of the Tornado and Storm Research Organisation. Atmos. Res., 56, 19-29, https://doi.org/ 10.1016/S0169-8095(00)00084-3.

Gallus, W. A., N. A. Snook, and E. V. Johnson, 2008: Spring and summer severe weather reports over the Midwest as a function of convective mode: A preliminary study. Wea. Forecasting, 23, 101-113, https://doi.org/10.1175/2007WAF2006120.1.

Gatzen, C. P., A. H. Fink, D. M. Schultz, and J. G. Pinto, 2020: An 18-year climatology of derechos in Germany. Nat. Hazards Earth Syst. Sci., 20, 1335-1351, https://doi.org/ 10.5194/nhess-20-1335-2020.

Goliger, A. M., and R. V. Milford, 1998: A review of worldwide occurrence of tornadoes. J. Wind Eng. Ind. Aerodyn., 74-76, 111-121, https://doi.org/10.1016/S0167-6105(98)00009-9.

Hersbach, H., and Coauthors, 2018: Operational global reanalysis: Progress, future directions and synergies with NWP. ECMWF ERA Rep. Series 27, 63 pp., https://doi.org/10.21957/ tkic6g3wm.

Holden, J., and A. Wright, 2004: UK tornado climatology and the development of simple prediction tools. Quart. J. Roy. Meteor. Soc., 130, 1009-1021, https://doi.org/10.1256/qj.03.45.

James, P., and K. Browning, 1979: Mesoscale structure of line convection at surface cold fronts. Quart. J. Roy. Meteor. Soc., 105, 371-382, https://doi.org/10.1002/qj.49710544404.

Jorgensen, D. P., Z. Pu, P. O. G. Persson, and W.-K. Tao, 2003: Variations associated with cores and gaps of a Pacific narrow cold frontal rainband. Mon. Wea. Rev., 131, 2705-2729, https://doi.org/ 10.1175/1520-0493(2003)131<2705:VAWCAG>2.0.CO;2.

King, J. R., M. D. Parker, K. D. Sherburn, and G. M. Lackmann, 2017: Rapid evolution of cool season, low-CAPE severe thunderstorm environments. Wea. Forecasting, 32, 763-779, https://doi.org/10.1175/WAF-D-16-0141.1.

Kirk, P. J., 2014: An updated tornado climatology for the UK: 1981-2010. Weather, 69, 171-175, https://doi.org/10.1002/wea.2247.

_, T. Prosser, and D. J. Smart, 2016: Tornadoes in the United Kingdom and Ireland: Frequency and spatial distribution. Extreme Weather: Forty Years of the Tornado and Storm Research Organisation (TORRO), R. K. Doe, Ed., Wiley Blackwell, 61-76.

Kitchen, M., and A. Illingworth, 2011: From observations to forecasts-Part XIII: The UK weather radar network-Past, present and future. Weather, 66, 291-297, https://doi.org/ 10.1002/wea.861.

Locatelli, J. D., J. E. Martin, and P. V. Hobbs, 1995: Development and propagation of precipitation cores on cold fronts. Atmos. Res., 38, 177-206, https://doi.org/10.1016/0169-8095(94)00093-S.

Matejka, T. J., R. A. Houze, and P. V. Hobbs, 1980: Microphysics and dynamics of clouds associated with mesoscale rainbands in extratropical cyclones. Quart. J. Roy. Meteor. Soc., 106, 29-56, https://doi.org/10.1002/qj.49710644704.

McDonald, J. R., K. C. Mehta, D. A. Smith, and J. Arn Womble, 2009: The enhanced Fujita scale: Development and implementation. Fifth Forensic Engineering Congress, Washington, DC, American Society of Civil Engineers, 719-728, https://doi.org/10.1061/ 41082(362)73.

Meaden, G. T., 1976a: Tornadoes in Britain: Their intensities and distribution in time and space. J. Meteor., 1, 242-251.

_ 1976b: Tornadoes of 12 January 1975 in England. J. Meteor., 1, 187-193.

_ 2016: Researching extreme weather in the United Kingdom and Ireland: The history of the Tornado and Storm Research Organisation, 1974-2014. Extreme Weather: Forty Years of the Tornado and Storm Research Organisation (TORRO), R. K. Doe, Ed., Wiley Blackwell, 1-14. 
and M. W. Rowe, 1985: The great tornado outbreak of 23 November 1981 in which North Wales, central and eastern England had 105 known tornadoes in about five hours. J. Meteor., 10, 295-300.

- , S. Kochev, L. Kolendowicz, A. Kosa-Kiss, I. Marcinoniene, M. Sioutas, H. Tooming, and J. Tyrrell, 2007: Comparing the theoretical versions of the Beaufort scale, the T-scale and the Fujita scale. Atmos. Res., 83, 446-449, https://doi.org/10.1016/ j.atmosres.2005.11.014.

Mulder, K. J., and D. M. Schultz, 2015: Climatology, storm morphologies, and environments of tornadoes in the British Isles: 1980-2012. Mon. Wea. Rev., 143, 2224-2240, https://doi.org/ 10.1175/MWR-D-14-00299.1.

Mulqueen, K. C., and D. M. Schultz, 2015: Non-classic extratropical cyclones on Met Office sea-level pressure charts: Double cold and warm fronts. Weather, 70, 100-105, https:// doi.org/10.1002/wea.2463.

Nolen, R., 1959: A radar pattern associated with tornadoes. Bull. Amer. Meteor. Soc., 40, 277-279, https://doi.org/10.1175/ 1520-0477-40.6.277.

Parker, M. D., and R. H. Johnson, 2000: Organizational modes of midlatitude mesoscale convective systems. Mon. Wea. Rev., 128, 3413-3436, https://doi.org/10.1175/1520-0493(2001)129<3413: OMOMMC $>2.0 . \mathrm{CO} ; 2$.

Parsons, D. B., and P. V. Hobbs, 1983: The mesoscale and microscale structure and organization of clouds and precipitation in midlatitude cyclones. VII: Formation, development, interaction and dissipation of rainbands. J. Atmos. Sci., 40, 559-579, https://doi.org/10.1175/1520-0469(1983)040<0559: TMAMSA $>2.0 . \mathrm{CO} ; 2$.

Reynolds, D. J., 1999: A revised tornado climatology of the U.K., 1960-1989. J. Meteor., 24, 290-321.

Schultz, D. M., 2005: A review of cold fronts with prefrontal troughs and wind shifts. Mon. Wea. Rev., 133, 2449-2472, https://doi.org/10.1175/MWR2987.1.
Sherburn, K. D., and M. D. Parker, 2014: Climatology and ingredients of significant severe convection in high-shear, lowCAPE environments. Wea. Forecasting, 29, 854-877, https:// doi.org/10.1175/WAF-D-13-00041.1.

, — - J. R. King, and G. M. Lackmann, 2016: Composite environments of severe and nonsevere high-shear, low-CAPE convective events. Wea. Forecasting, 31, 1899-1927, https:// doi.org/10.1175/WAF-D-16-0086.1.

Smart, D. J., and K. A. Browning, 2009: Morphology and evolution of cold-frontal misocyclones. Quart. J. Roy. Meteor. Soc., 135, 381-393, https://doi.org/10.1002/qj.399.

Snow, J. T., and A. Wyatt, 1997: Back to basics: The tornado, nature's most violent wind: Part I-World-wide occurrence and categorisation. Weather, 52, 298-304, https://doi.org/10.1002/ j.1477-8696.1997.tb05525.x.

Trapp, R. J., and M. L. Weisman, 2003: Low-level mesovortices within squall lines and bow echoes. Part II: Their genesis and implications. Mon. Wea. Rev., 131, 2804-2823, https://doi.org/ 10.1175/1520-0493(2003)131<2804:LMWSLA>2.0.CO;2.

— S. A. Tessendorf, E. S. Godfrey, and H. E. Brooks, 2005: Tornadoes from squall lines and bow echoes. Part I: Climatological distribution. Wea. Forecasting, 20, 23-34, https://doi.org/10.1175/WAF-835.1.

Tyrrell, J., 2003: A tornado climatology for Ireland. Atmos. Res., 67-68, 671-684, https://doi.org/10.1016/S0169-8095(03)00080-2.

van den Broeke, M. S., D. M. Schultz, R. H. Johns, J. S. Evans, and J. E. Hales, 2005: Cloud-to-ground lightning production in strongly forced, low-instability convective lines associated with damaging wind. Wea. Forecasting, 20, 517-530, https:// doi.org/10.1175/WAF876.1.

Weisman, M. L., and R. J. Trapp, 2003: Low-level mesovortices within squall lines and bow echoes. Part I: Overview and dependence on environmental shear. Mon. Wea. Rev., 131, 2779-2803, https://doi.org/10.1175/1520-0493(2003)131<2779: LMWSLA $>2.0 . \mathrm{CO} ; 2$. 